\title{
EPISÓDIOS INTRUSIVOS NO ARCO DE PONTA GROSSA, DETERMINADOS ATRAVÉS DE UM ESTUDO PALEOMAGNÉTICO
}

\author{
MARIA IRENE BARTOLOMEU RAPOSO
}

\begin{abstract}
INTRUSIVE EPISODES IN THE PONTA GROSSA ARCH, DETERMINED B Y A PALEOMAGNETIC STUDY. This work presents paleomagnetic data on the mafic dyke swarm associated with the tectonic structure known as the Ponta Grossa Arch. It is generally accepted that the dykes were emplaced when this structure were already well developed, during the Lower Cretaceous. The existing faults and fractures were then filled with magmatic material, mainly of basic composition giving rise to the so called Ponta Grossa Swarm. For the paleomagnetic analyses, 127 dykes were sampled which are widely distributed in the whole area of the Ponta Grossa Arch. These dykes cut the Paraná Basin sediments, mainly Paleozoic in age, as well as the crystalline basement. About 400 hand-samples and cylinders were collected and oriented by both magnetic and sun compasses. The magnetic stability was investigated by both thermal and alternate magnetic field demagnetization methods. The characteristic remanent magnetization of each sample was identified through Zijderveld diagrams. Normally 3 specimens from each sample were submitted to the proper fields or temperatures. The mean magnetization direction of each dyke was calculated by averaging the data from the corresponding specimens. Statistic parameters associated to the means were calculated by Fisher's statistics (1953). Paleomagnetic directions recorded within each of the areas where the dykes are concentrated: Fartura, Sapopema, Telêmaco Borba, Curitiba and Guapiara, show significant differences suggesting that the dykes were emplaced in different intrusive phases. A statistical comparison of the magmatic phases from different areas indicate that frequently not all the areas were active at the same time. It is suggested that the Ponta Grossa Arch was affected by nine main intrusive episodes, from which five took place during a normal polarity geomagnetic interval, three took place a during reversed interval and one occurred when the geomagnetic field presented anomalous directions. This latter episode was only recorded in Guapiara and Fartura. In general each episode affected two or more areas. However, one of the normal field episodes was identified only in Fartura and one of the reversed field episodes affected only Curitiba.
\end{abstract}

Keywords: Mafic dikes, Ponta Grossa Arch, Paleomagnetism.

RESUMO Foi realizado estudo paleomagnético do enxame de diques associado à estrutura tectônica de soerguimento conhecida como Arco de Ponta Grossa. Acredita-se que os diques foram colocados quando essa estrutura encontrava-se no seu ponto máximo de evolução ocorrido no Cretáceo Inferior, quando originaram-se inúmeras falhas e fraturas que foram preenchidas por material magmático, essencialmente, básico. Desse modo, o enxame de diques ficou conhecido como enxame de diques do Arco de Ponta Grossa. Foram analisados 127 corpos intrusivos amplamente distribuídos por toda a área ocupada pelo Arco de Ponta Grossa, que cortam tanto os sedimentos, principalmente Paleozóicos, da Bacia do Paraná como as rochas do embasamento cristalino. Um total de cerca de 400 amostras de mão e cilindros, orientados com auxílio de bússolas magnética e solar, foram coletados e analisados. Estudou-se a estabilidade magnética das amostras através de desmagnetizações térmica e por campos magnéticos alternados. Procurou-se identificar a magnetização remanescente característica das amostras com auxílio do diagrama de Zijderveld e submeteu-se, pelo menos, 2 ou 3 espécimens da mesma amostra a campos ou temperaturas selecionadas. A direção média de magnetização de cada dique foi calculada através da média das direções dos espécimens correspondentes. Os parâmetros estatísticos foram obtidos através de Fisher (1953). Analisou-se individualmente os grupos de direções de magnetização relativos aos diques afiorantes nas áreas de concentração: Fartura, Sapopema, Telêmaco Borba, Curitiba e Guapiara. Os dados mostraram que há diferenças significativas nas direções paleomagnéticas dos diques pertencentes a uma mesma área, sugerindo que estes corpos foram colocados em fases ou episódios intrusivos distintos. Através de uma comparação estatística entre as fases intrusivas das diversas áreas, verificou-se que nem sempre essas áreas estiveram, ativas simultaneamente. Desse modo, sugere-se que o Arco de Ponta Grossa foi afetado por nove episódios intrusivos principais, dos quais cinco ocorreram durante um período de campo geomagnético normal, três durante um período de campo geomagnético reverso e um durante um campo de transição. Este último só foi registrado em Guapiara e Fartura. De modo geral, cada episódio encontra correspondente em duas ou mais áreas. Entretanto, um dos episódios de campo geomagnético normal foi identificado somente em Fartura e outro, de campo geomagnético reverso, somente em Curitiba.

Palavras-chaves: Diques máficos, Arco de Ponta Grossa, Paleomagnetismo.

INTRODUÇÃO No Brasil ocorrem inúmeros enxames de diques máficos tanto Pré-Cambrianos como Fanerozóicos. No entanto, ao contrário de outras regiões do mundo, os enxames Fanerozóicos são mais abundantes (Oliveira \& Montes 1984); entre eles destacam-se os de idade Mesozóica por apresentarem maior densidade de diques, sendo que estes possuem grande extensão, além de estarem relacionados com a ruptura dos continentes Sul-Americano e Africano (Sial et al. 1987).

Entre os enxames de diques máficos Mesozóicos aquele que ocorre inserido quase que totalmente no Estado do Paraná, representa o mais expressivo enxame de diques
Fanerozóicos já documentados no Brasil (Oliveira \& Montes 1984). Parece consenso geral que este enxame está associado ao desenvolvimento da estrutura tectônica de arqueamento conhecida como Arco de Ponta Grossa. Deste modo, o enxame de diques ficou conhecido como enxame de diques máficos do Arco de Ponta Grossa.

Durante o Cretáceo Inferior ocorreu um intenso vulcanismo que preencheu grande parte da Bacia do Paraná e estabeleceram-se, então, os enxames de diques expostos nas bordas da Bacia, entre eles o enxame associado ao Arco de Ponta Grossa. Este enxame é particularmente importante porque seus diques apresentam-se muito espessos com gran- 
dês extensões e direção preferencial NW. Este fato induziu a um relacionamento genético direto entre os diques e as rochas vulcânicas pertencentes à Formação Serra Geral da Bacia do Paraná. Entretanto estudos geoquímicos efetuados por Piccirillo et al. (1988, 1989, 1990) e Pinese (1989) mostraram que os diques são geoquimicamente semelhantes somente às rochas vulcânicas da Região Norte da Bacia do Paraná (isto é, ao norte do lineamento do Rio Piquiri, Fig.1). Estudos paleomagnéticos realizados por Ernesto et al. (1990) e Raposo \& Ernesto (1989), em seqüências de derrames da Formação Serra Geral e nas rochas intrusivas do Arco de Ponta Grossa, mostraram que os diques são mais jovens que as rochas vulcânicas da Bacia do Paraná.

Este trabalho apresenta um estudo paleomagnético pormenorizado do enxame de diques do Arco de Ponta Grossa, o qual torna-se essencial ao conhecimento dos episódios intrusivos ocorridos no Arco. Neste caso o método paleomagnético é particularmente importante pois, é capaz de detectar mudanças significativas do campo magnético terrestre chamadas de variação secular, além das inversões de polaridade, o que permite relacioná-las com tempos diferentes de colocação dos corpos os quais não são detectados por métodos radiométricos tais como $\mathrm{K}-\mathrm{Ar}$ e $\mathrm{Rb}-\mathrm{Sr}$.

Foram estudados paleomagneticamente 127 corpos intrusivos amplamente distribuídos pelo Arco de Ponta Grossa tendo por objetivo estudar detalhadamente a atividade intrusiva ocorrida no Arco, além de contribuir para uma melhor compreensão do evento tectono-magmático ocorrido no sul do Brasil durante o Cretáceo.
Resultados paleomagnéticos preliminares de alguns dos diques incluídos neste trabalho, foram apresentados por Raposo \& Ernesto (1989) e revelaram-se discordantes daqueles apresentados por Ernesto et al. (1990). Isto levou as autoras a concluirem que poderia haver dentro do Arco, áreas onde os diques apresentassem diferentes idades de magnetização, uma vez que parte dos dados referia-se a diques aflorantes na área do Pré-Cambriano (Ernesto et al., 1990) e os demais (Raposo \& Ernesto, 1989), a diques que cortam os sedimentos Paleozóicos. Como será visto no decorrer deste trabalho, esta hipótese não pode ser descartada embora a totalidade dos dados, não aponte para diferenças significativas de idades.

\section{ASPECTOS GEOLÓGICOS DO ARCO DE PONTA GROSSA E DO ENXAME DE DIQUES AS} SOCIADO Arco de Ponta Grossa O Arco de Ponta Grossa é uma megaestrutura de soerguimento cujo eixo orienta-se a N W com mergulho para o interior da Bacia do Paraná. Localiza-se na borda sudeste do território brasileiro e é bem visível nos mapas geológicos pela reentrância da borda oriental da Bacia do Paraná (Fig. 1).

Almeida (1983) e Ferreira (1982) admitiram que a área crustal onde situa-se o Arco de Ponta Grossa apresentava tendência ao soerguimento desde o Devoniano. Essa estrutura configurou-se como área positiva no Permiano e condicionou a deposição dos sedimentos na Bacia do Paraná, subdividindo-a em duas sub-bacias denominadas de São Paulo e Santa Catarina. Entretanto durante o Triássico-

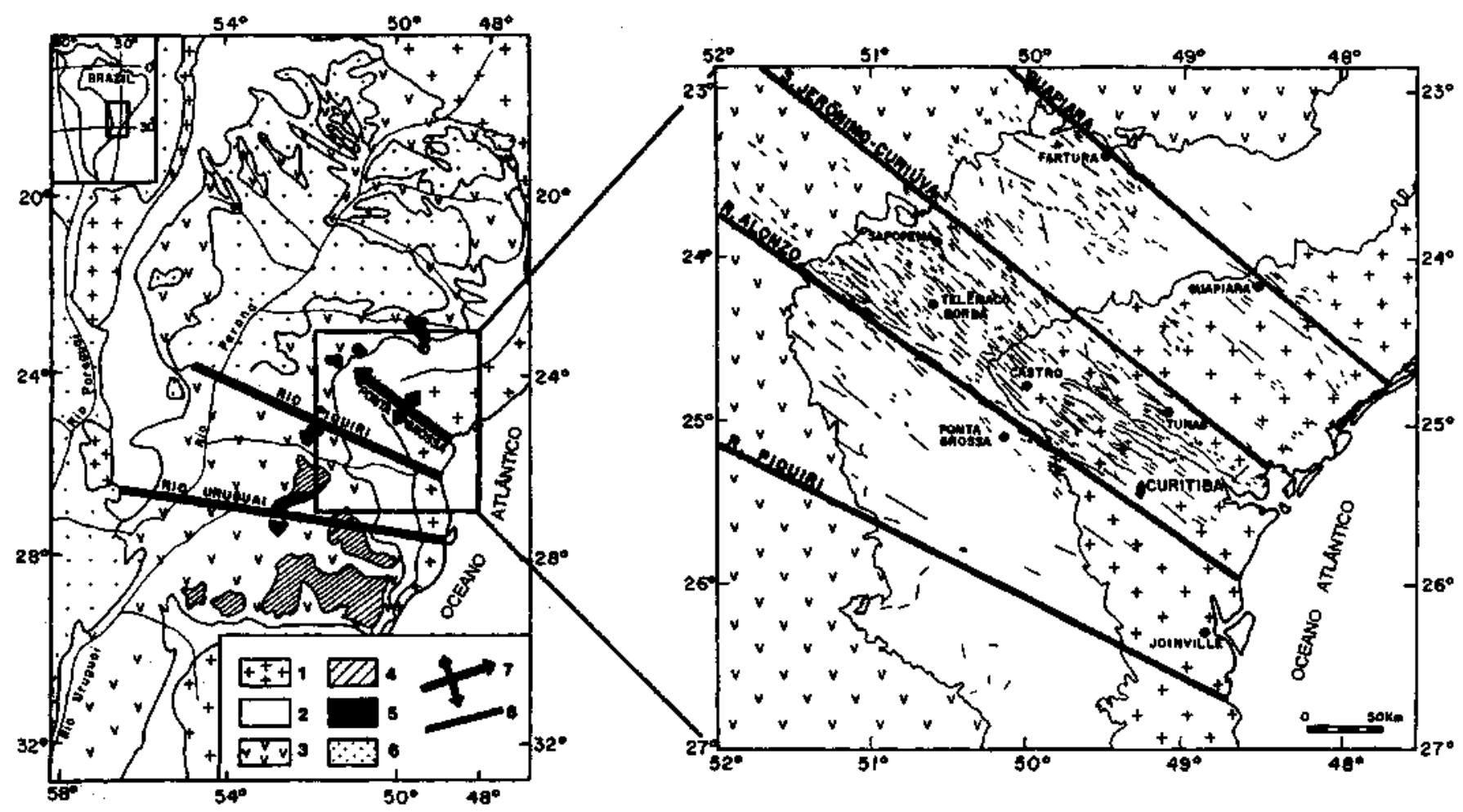

Figura 1 - Mapa geológico generalizado da Bacia do Paraná, destacando o Arco de Ponta Grossa, 1 - embasamento cristalino; 2 - sedimentos pré-vulcânicos (principalmente Paleozóicos); 3 - derrames básicos-intermediários da Formação Serra Geral; 4 - derrames ácidos tipo Palmas da Formação Serra Geral; 5 - derrames ácidos tipo Chapecó da Formação Serra Geral; 6 - sedimentos pós-vulcânicos (principalmente Cretáceo Superior); 7 - estrutura tipo arco; 8 - lineamentos tectônicos elou magnéticos

Figure 1 - Generalized geological map of the Paraná Basin showing the Ponta Grossa Arch. 1 - crystalline basement; 2 - prevolcanic sediments; 3 - basic to intermediate flood volcanics from Serra Geral Formation; 4 - acid lava flows (Palmas type); 5 - acid lava flows (Chapecó type); 6 - postvolcanic sediment (mainly upper Cretaceous); 7 - arch-type structure; 8 - tectonic and/or magnetic lineaments 
Jurássico o soerguimento tornou-se mais pronunciado separando mais nitidamente as duas sub-bacias onde foram acumulados os sedimentos continentais das Formações Pirambóia, na sub-bacia de São Paulo, e Rosário do Sul, na subbacia de Santa Catarina. Porém, somente entre o Jurássico e o Cretáceo Inferior é que as feições do Arco de Ponta Grossa mais se realçaram e adquiriram a configuração que hoje apresentam (Almeida, 1986).

Asmus (1981) concluiu que o Arco de Ponta Grossa não existia até o final do Permiano, admitiu a hipótese de que o soerguimento crustal do Arco tenha ocorrido no Triássico e tenha sido responsável pelo aparecimento de duas subbacias na porção sudeste da Bacia do Paraná, uma ao norte do Arco, onde acumularam-se os sedimentos da Formação Pirambóia, e outra ao sul do Arco onde depositaram-se os sedimentos da Formação Rosário do Sul.

Embora em termos de idade, o início do soerguimento do Arco de Ponta Grossa seja motivo de controvérsias, parece consenso geral que o clímax desse soerguimento tenha ocorrido no Jurássico-Cretáceo Inferior, juntamente com o evento tectono-magmático da reativação Wealdeniana definida por Almeida (1967), que foi responsável pelo vulcanismo da Bacia do Paraná e das Bacias costeiras de Santos e Campos (Almeida, 1983; Asmus \& Porto, 1980). Nesse intervalo desenvolveram-se no Arco grandes fraturas e falhas de distensão paralelas ao seu eixo $(\mathrm{NW}) \mathrm{e}$, portanto, transversais às estruturas do embasamento e que propiciaram as intrusões básicas e alcalinas (Almeida, 1986). Uma provável estensão desse evento originou o enxame de diques que aflora desde o litoral norte paulista até o Estado do Rio de Janeiro e o enxame de Florianópolis (SC). Associadas, ainda, ao magmatismo básico, ocorreram inúmeras intrusões alcalinas.

Através da interpretação das anomalias magnéticas obtidas por levantamentos aeromagnéticos da porção centrooriental da Bacia do Paraná e, portanto, pequenas porções da área ocupada pelo Arco de Ponta Grossa, Ferreira et al. (1981) e Ferreira (1982) comprovaram a existência dos falhamentos no Arco de Ponta Grossa, já referidos por Vieira (1973) e Algarte (1972), batizando-os de Alinhamento de Guapiara, Alinhamento São Jerônimo-Curiúva e Alinhamento do Rio Alonzo.

Os dados aeromagnéticos permitiram a Ferreira (1982) definir o Alinhamento do Rio Piquiri, além de definir a geometria do Arco, estabelecer seus limites e dividi-lo em três grandes regiões. Cabe ressaltar que em muitos locais os alinhamentos aeromagnéticos foram inferidos, através de estudos de sensoriamento remoto, devido à ausência de aerolevantamentos.

De acordo com Ferreira (1982) o limite norte do Arco de Ponta Grossa é marcado pelo Alinhamento de Guapiara, que passa próximo à cidade de Fartura, estende-se desde Iguape (leste) até o Rio Paraná (oeste), apresenta $600 \mathrm{~km}$ de extensão e larguras variáveis de 20 a $100 \mathrm{~km}$. A região norte do Arco está compreendida entre os Alinhamentos de Guapiara e São Jerônimo-Curiúva (Fig. 1).

A região central é definida pelos Alinhamentos São Jerônimo-Curiúva e do Rio Alonzo, caracteriza-se por intenso fraturamento e falhamentos de pequeno rejeito. $\mathrm{O}$ limite sul do Arco é caracterizado pelo Alinhamento do Rio Piquiri que é orientado a N60-65W, com extensão de 115 $\mathrm{km}$ e largura máxima de $20 \mathrm{~km}$. A região sul é limitada pelos Alinhamentos do Rio Alonzo e do Rio Piquiri.

Segundo esses limites o Arco de Ponta Grossa (Fig. 1) situa-se quase que totalmente no Estado do Paraná, restando pequenas parcelas nos Estados de São Paulo e Santa Catarina e ocupa uma área aproximada de $134.000 \mathrm{~km}^{2}$.

Enxame de Diques Estudos pioneiros sobre os diques parecem ser os de Marini et al. (1967) e Fúlfaro \& Suguio (1967). Os primeiros pesquisadores estudaram o
Primeiro Planalto do Paraná (região central do Arco) e verificaram a ocorrência de diques paralelos orientados a NW-SE, com espessuras variáveis de 20 a $50 \mathrm{~m}$, podendo atingir localmente $600 \mathrm{~m}$ e confinados numa faixa de $70 \mathrm{~km}$ de largura que se estendia desde o vale do rio Ivaí até o litoral paranaense. A frequência de diques era em torno de 1,5 dique $/ \mathrm{km}$ e, às vezes, 4 diques $/ \mathrm{km}$.

Fúlfaro \& Suguio (1967) estudaram três áreas de ocorrência de diques: 1) Rodovia do Café (do km 160 até a Serra do Cadeado - região Central do Arco), onde observaram diques direcionados segundo dois sistemas N40-45W e N25E, com espessuras de $52 \mathrm{~m}$ até $950 \mathrm{~m}$ (média $200 \mathrm{~m}$ ) e extensões de até $4 \mathrm{~km}$; 2) Rodovia Piraju-Fartura, próximo a Fartura (região norte do Arco); nesta região foram encontrados 5 diques de direções $\mathrm{N} 40-45 \mathrm{~W}$ com espessuras compreendidas entre $60-100 \mathrm{~m}$ (média $80 \mathrm{~m}$ ) em $7 \mathrm{~km}$ da rodovia; os autores sugerem que os diques são os possíveis condutos alimentadores das rochas vulcânicas da Formação Serra Geral, uma vez que eles se colocam sob os derrames; 3) Rodovia Tambaú-Santa Rosa do Viterbo, onde ocorrem diques orientados predominatemente a N60-70E e secundariamente a N40-45W e com espessura média de $200 \mathrm{~m}$.

Os autores citados concluíram, de modo geral, que os diques formam sistemas paralelos e orientados preferencialmente a NW, embora a direção NE também esteja presente, ocasionando sistemas secundários de direções perpendiculares nas regiões do Paraná e Sul do Estado de São Paulo. Entretanto a situação é exatamente inversa na área situada ao norte do Estado de São Paulo, onde a direção NE é predominante. Fúlfaro \& Suguio foram contrários às afirmações de Bigarella e Salamuni (1967; in Fúlfaro \& Suguio, 1967) de que sistemas paralelos com direções NE eram insignificantes, ao menos, para o flanco norte da Bacia do Paraná, assim como também não era verdadeiro que as concentrações de diques diminuíam a distâncias maiores da área da cidade de Ponta Grossa.

Embora os estudos iniciais sobre os diques tenham sido baseados em dados de campo, os mesmos não foram efetuados em todas as áreas de ocorrência dos diques. Atualmente o método aeromagnético está sendo bastante aplicado no mapeamento de diques, além da metodologia tradicional de sensoriamento remoto.

Ferreira (1982) comparou as anomalias aeromagnéticas dos levantamentos efetuados na Bacia do Paraná, os quais cobrem pequenas porções do Arco de Ponta Grossa, com mapas geológicos existentes, onde geralmente os diques são assinalados com auxílio de fotos aéreas e imagens de satélite, e concluiu que as anomalias representavam diques. No entanto, quando as anomalias não encontravam correspondência com os mapas geológicos, o autor inferiu diques não aflorantes. Os mapas aeromagnéticos apresentam anomalias com direções predominantes NW, inúmeras com direção NE e poucas E-W. Ferreira (1982) considerou menos expressivas as anomalias NE e E-W e associou somente aquelas com direções NW a diques. Entretanto cabe ressaltar que a direção NE representa a orientação principal do sistema de fraturas do embasamento cristalino e também ocorre na Bacia do Paraná (Soares et al. 1982; Zalán et al 1988). Portanto, as anomalias NE e E-W poderiam igualmente representar diques.

Dessa maneira os diques do Arco de Ponta Grossa têm sido considerados quase que exclusivamente com direção NW. Um mapa de ocorrência desses diques, com controle rígido de campo, parece não existir. Os mapeamentos geológicos efetuados em diversas áreas do Arco não dão muita importância para o posicionamento real dos diques, uma vez que eles podem ser marcados através de anomalias aeromagnéticas, imagens de satélite ou ainda uma combinação de ambas as metodologias. Assim, os mapas geológicos do Arco de Ponta Grossa, no tocante aos diques, são errône- 
os pois, mostram uma quantidade muito grande de diques que não foram encontrados no campo. Estes mapas deveriam ser reanalisados tendo em vista que Ussami et al. (1991) mostraram através de um estudo integrado de aeromagnetometria, magnetometria terrestre e magnetismo de rocha que nem sempre as anomalias magnéticas existentes nos mapas aeromagnéticos nas escalas convencionais (por exemplo, 1:1000.000) correspondem a diques.

As medidas, quer da direção estrutural quer da espessura dos diques, são algumas vezes difíceis de serem efetuadas em campo, devido à ausência dos contatos desses corpos com as encaixantes ou a não continuidade do corpo mesmo que os contatos existam. No entanto, mesmo com esta dificuldade foi possível obter, com certa confiança, algumas medidas de direções tanto para NW como para NE concordantes, portanto, com Fúlfaro \& Suguio (1967) (Tabelai). Resultados obtidos por Raposo \& Ernesto (1991) com a aplicação da técnica de anisotropia de suscetibilidade magnética, permitiram definir melhor as direções dos diques.

Os diques, na realidade, não são uniformemente distribuídos por toda região ocupada pelo Arco de Ponta Grossa, mas encontram-se concentrados sobretudo nas áreas aqui designadas de Fartura (SP) e Guapiara (SP) (porções NE e $\mathrm{SE}$, repectivamente, do Arco entre os alinhamentos aeromagnéticos de São Jerônimo-Curiúva e Guapiara, próximo a este último, (Fig. 1); Sapopema (PR), Telêmaco Borba (PR) e Curitiba (PR) (porções centro - as duas primeiras - e SE, do Arco entre os alinhamentos de São Jerônimo-Curiúva e do Rio Alonzo, (Fig. 1), sendo escassas as ocorrências ao sul do alinhamento do Rio Alonzo. Na Tabela 1 são apresentadas as coordenadas geográficas, as espessuras (larguras), as direções estruturais medidas em campo e o número de amostras coletadas, para todos os corpos estudados, e a localização encontra-se na Figura 2.

De modo geral os diques são subverticais a verticais e cortam tanto os sedimentos, principalmente Paleozóicos, da Bacia do Paraná como as rochas Pré-Cambrianas do embasamento cristalino na porção mais oriental do Arco (Fig. 1 e 2).

$\mathrm{Na}$ área de Fartura os corpos intrusivos são predominantemente diques, embora existam alguns na forma de sills como apontado por Fúlfaro \& Suguio (1974). Os sills são por vezes difíceis de serem identificados devido aos processos erosivos ocorridos na região, além da proximidade dos derrames da Formação Serra Geral. Os corpos intrusivos alojam-se nos sedimentos do Grupo Itararé e nas Formações Rio Bonito, Palermo, Tatui, Rio do Rasto, Irati, Corumbataí, Pirambóia e Botucatu (Fúlfaro \& Suguio, 1974; IPT, 1981). Em determinados locais, os diques cortam as rochas vulcânicas ácidas e básicas da Formação Serra Geral. Apresentam-se orientados preferencialmente a NW, embora orientações a NE e N-S também tenham sido encontradas (Tabela 1); suas espessuras são variáveis desde poucos centímetros até uma centena de metros, média de $50 \mathrm{~m}$, Tabela 1).

$\mathrm{Na}$ área de Sapopema os diques cortam os sedimentos das Formações Furnas, Ponta Grossa, Rio Bonito* Palermo, Irati e Teresina, além do Grupo Itararé (Mineropar, 1989). Orientam-se preferencialmente a NW, porém, direções a NE e N-S também foram econtradas. Nesta área os diques são ligeiramente mais espessos em relação às demais áreas e apresentam uma espessura média de $90 \mathrm{~m}$, atingindo até $500 \mathrm{~m}$ (ponto 29, Tabela 1).

Em Telêmaco Borba os diques alojam-se principalmente nos sedimentos do Grupo Itararé e das Formações Ponta Grossa e Furnas (Mineropar, 1989). Orientam-se quase na mesma proporção a NW (13 diques) e a NE (10 diques), apresentam espessuras variáveis entre 20 a $150 \mathrm{~m}$, com média em torno de $50 \mathrm{~m}$ (Tabela 1).

Os diques da área de Curitiba cortam as rochas do PréCambriano, principalmente os granitos alcalinos fácies Graciosa, Anhangava, Marumby e Serra da Igreja, xisto e gnaisses do complexo Serra Negra, as Formações Itaiacoca e Votuverava do Grupo Açungui e as Formações Água Clara e Perau do Grupo Setuva (Mineropar, 1989). Orientam-se predominantemente a NW, entretanto, as direções NE, N-S e E-W também foram encontradas. Apresentam espessuras médias de $50 \mathrm{~m}$, com intervalo de poucos centímetros até $150 \mathrm{~m}$ (Tabela 1).

$\mathrm{Na}$ área de Guapiara os diques apresentam, como encaixantes, as rochas do embasamento cristalino, principalmente os granitos sintectônicos da fácies Cantareira e o Grupo Açungui (IPT, 1981). Orientam-se segundo direções NW e NE. Suas espessuras são de difícil determinação devido ao alto grau de intemperismo, podendo variar de dezenas a centenas de metros (Tabela 1).

Em geral não se observa grandes variações tanto de espessura como de granulação entre os diques que cortam as rochas do embasamento cristalino e os sedimentos da Bacia do Paraná. Entretanto, na área de Sapopema (Tabela 1), encontram-se diques ligeiramente mais espessos e de granulação mais grosseira. Este fato pode indicar que o embasamento cristalino já estava exposto quando ocorreu a atividade intrusiva.

Os diques são representados, predominantemente, por andesi-basaltos constituídos essencialmente de plagioclásios, piroxênios (augita e pigeonita), óxidos de $\mathrm{Fe}$ e $\mathrm{Ti}$ principalmente titanomagnetitas e, subordinadamente, pirita e calcopirita. Porém nas áreas de Fartura (1 dique) e Curitiba ( 3 diques), ocorrem diques riodacíticos compostos por plagioclásios, piroxênios (augita e pigeonita), feldspato alcalino, titanomagnetitas, apatita e quartzo. Estes diques apresentam composição química (Benini, 1992) semelhante às rochas vulcânicas do tipo Chapecó, definido por Bellieni et al. (1984), da Formação Serra Geral.

Pinese (1989) e Piccirillo et al. (1990) mostram, de modo geral, que os diques possuem valores de $\mathrm{TiO}_{2}$ baixo $(<2 \%)$, intermediário $(2-3 \%)$ e alto $(>3 \%)$ e apresentam composição química similar às rochas vulcânicas da Região Norte da Bacia do Paraná (ao norte do alinhamento do Rio Piquiri,

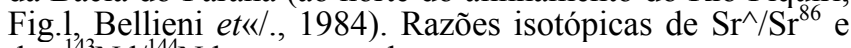
de ${ }^{143} \mathrm{Nd} /{ }^{144} \mathrm{Nd}$, apresentadas por esses mesmos autores, também são semelhantes àquelas das rochas vulcânicas, particularmente, os diques básicos da área de Fartura e as vulcânicas adjacentes. Os diques ácidos apresentam valores de razões isotópicas mais baixos do que as vulcânicas ácidas da área de Fartura indicando, assim, que os diques são poucos ou não contaminados.

Estudos geoquímicos realizados nas mesmas amostras analisadas no presente trabalho (Benini, 1992), indicam diferenças geoquímicas entre as cinco áreas (onde os diques acham-se concentrados) que, embora não muito acentuadas, são significativas. Sob esse aspecto os diques das áreas de Fartura e Guapiara são semelhantes e apresentam-se mais evoluídos em relação às demais áreas. Os diques de Curitiba apresentam valores mais elevados de $\mathrm{MgO}(>6 \%)$ e são os mais primitivos do Arco de Ponta Grossa. Os diques das áreas de Sapopema e Telêmaco Borba são semelhantes entre si e ocupam uma posição intermediária entre aqueles das áreas de Fartura-Guapiara e Curitiba.

Em termos de idade, os diques apresentam um valor médio de $132 \pm 10 \mathrm{Ma}$, obtido com o método radiométrico $\mathrm{K}-\mathrm{Ar}$, com intervalo de 114-144 Ma (Pinese, 1989). Este valor é concordante com a idade atribuída à fase de maior atividade vulcânica da Bacia do Paraná, que corresponde a 130-135 Ma, sendo o intervalo de 112-155 Ma para todo o vulcanismo da Bacia (Rocha Campos et al. 1988).

Entretanto as idades das rochas vulcânicas da Bacia do Paraná foram obtidas pelos métodos K-Ar e Rb-Sr. Desse modo, o amplo intervalo de tempo dado para todo o vulcanismo da Bacia, parece não ser verdadeiro pois, é conflitante com os dados de Ernesto et al. (1990) e Renne et al (1992). 
Tabela 1 - Coordenadas geográficas, espessuras (larguras) e direção estrutural dos 127 diques estudados. $N$ corresponde ao número de amostras coletadas

Table 1 - Geographic coordinates, thickness (width) and strike of the 127 sudied dikes. N corresponds to number of the collected samples

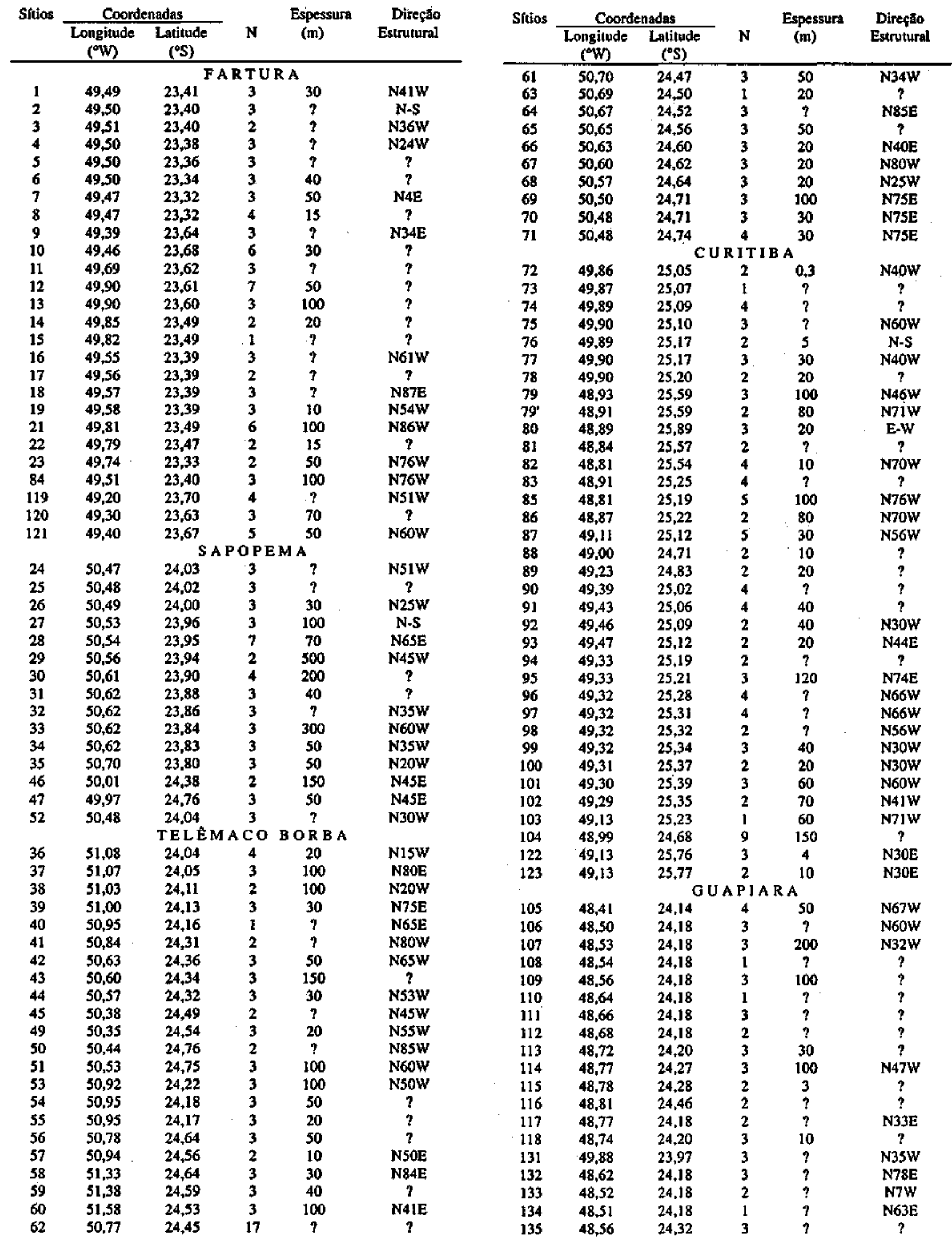




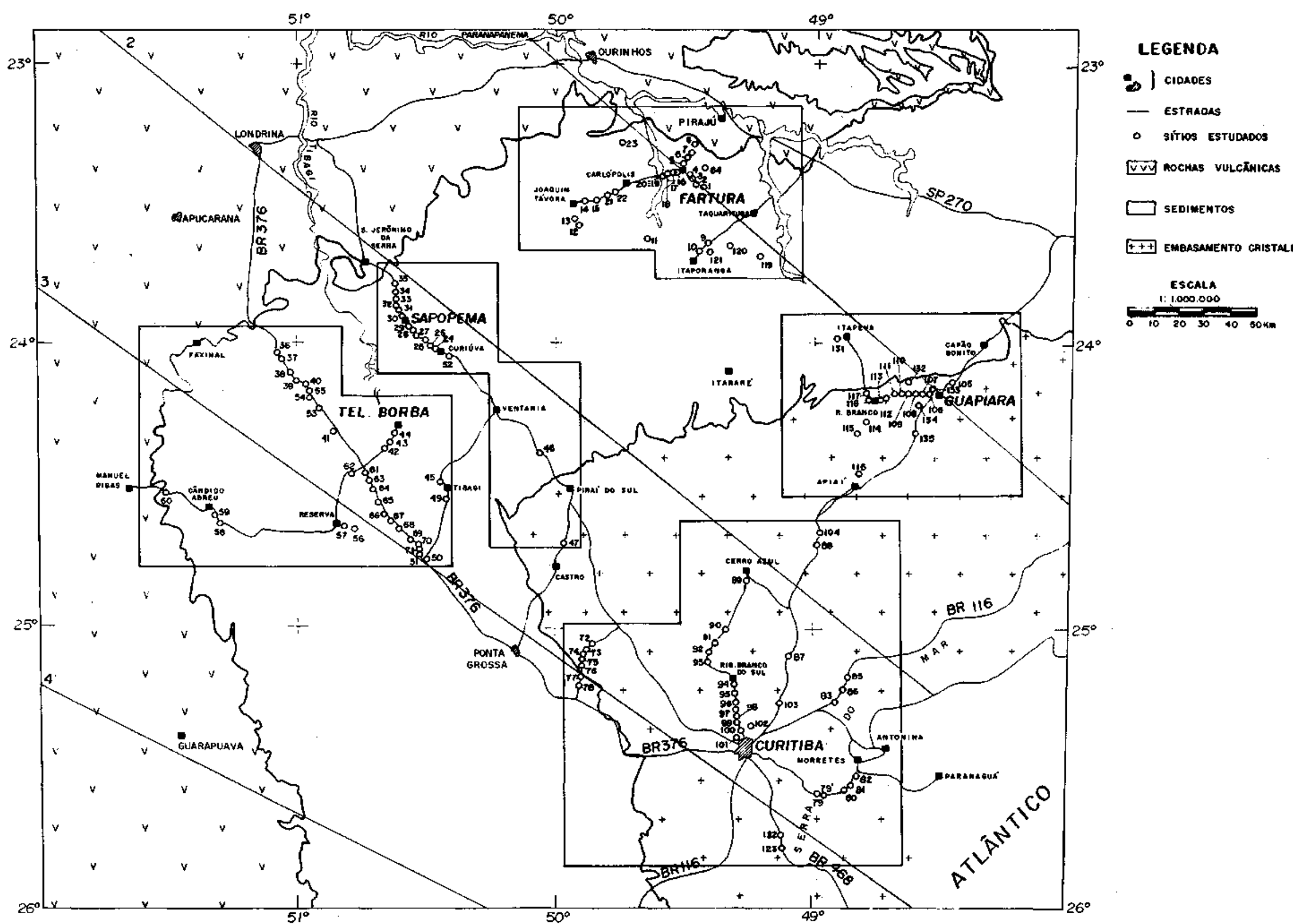

Figura 2-Mapa de localização dos diques estudados, destacando as áreas estabelecidas neste trabalho, 1-Alinhamento de Guapiara, 2-Alinhamento São JerônimoCuríuva,3-Alinhamento do Rio Alonzo e 4-Alinhamento do Rio Piquiri

Figure 2 - Localization map of the studied dikes. The areas detached were established in this paper. 1-Guapiara lineament, 2-São Jerônimo -Curiuva lineament, 3-Rio Alonzo lineament and 4-Rio Piquiri lineament 
Estes autores através de estudos, respectivamente, paleomagnéticos e geocronológicos (método Ar-Ar) de seqüências de lavas da Região Sul da Bacia do Paraná (sul do lineamento do Rio Uruguai, Fig. 1), concluíram que o empilhamento das lavas foi extremamente rápido. Os dados Ar-Ar obtidos revelaram uma idade de $133 \pm 1$ Ma para o vulcanismo na parte Sul da Bacia e um intervalo de duração de $1 \mathrm{Ma}$.

\section{PROCEDIMENTO EXPERIMENTAL Amostragem}

As amostras analisadas foram coletadas em afloramentos ao longo de rodovias existentes. Coletou-se um total de 400 amostras orientadas (blocos de mão e cilindros) que correspondem a 127 corpos intrusivos amplamente distribuídos no Arco de Ponta Grossa (Fig. 2).

Para a orientação das amostras utilizou-se bússola magnética e, sempre que possível, bússola solar. Procurou-se coletar amostras distribuídas em toda a largura do corpo intrusivo, isto é, de contato a contato. Desse modo o número de amostras coletadas por sítio (dique) foi variável. Procurou-se coletar no mínimo 3 amostras para cada um deles (Tabela 1). No entanto, para corpos muito espessos e sempre que as condições do afloramento permitiam a amostragem foi mais densa. Esse procedimento teve por objetivo detectar possíveis variações na direção de magnetização em corpos muito espessos. Estas variações podem estar relacionadas com o tempo de resfriamento do corpo, que pode ser suficientemente longo para que sejam registradas variações geomagnéticas importantes.

Procurou-se amostrar o maior número possível de diques, entretanto, nem todos puderam ser amostrados devido ao alto grau de alteração em que se encontravam. Em afloramentos onde não foi possível coletar amostra-de-mão, utilizou-se um perfurador portátil, que corresponde a uma moto-serra adaptada para extrair cilindros diretamente do afloramento. Antes de serem extraídos, os cilindros foram orientados.

\section{Medidas da Magnetização Remanescente e Es- tabilidade Magnética das Amostras Estudadas}

Para efetuar as medidas de magnetização remanescente das amostras, foi necessário prepará-las de forma conveniente. As amostras foram cortadas em cilindros orientados de 2,5 $\mathrm{cm}$ de diâmetro de onde foram cortados discos (espécimens) de $2,5 \mathrm{~cm}$ de altura.

Inicialmente mediu-se a magnetização remanescente natural (MRN) dos espécimens (discos) em magnetômetro tipo rotativo da Molspin Ltd. A seguir, testou-se a estabilidade magnética das amostras pelos processos convencionais de desmagnetização por campos magnéticos alternados e térmico.

Para testar a estabilidade magnética das amostras pelo processo de desmagnetização por campos magnéticos alternados, submeteu-se um espécimen (disco-piloto) de cada amostra a etapas sucessivas de desmagnetização, a partir de campos com intensidade de $5 \mathrm{mT}$ e até o máximo de $80 \mathrm{mT}$ ou $100 \mathrm{mT}$, em intervalos de $5 \mathrm{mT}$. Em alguns casos reduziu-se o intervalo para 2 ou $3 \mathrm{mT}$. Algumas amostras, embora poucas, foram desmagnetizadas até campos de 180 ou $190 \mathrm{mT}$. Ao final de cada etapa de desmagnetização mediu-se novamente a magnetização remanescente.

A desmagnetização térmica foi realizada em um segundo disco-piloto de cada amostra, a partir de $150^{\circ} \mathrm{C}$ até, em geral, $600^{\circ} \mathrm{C}$ com incrementos de $50^{\circ} \mathrm{C}$ até $500^{\circ} \mathrm{C}$ e intervalos menores de 20 ou $30^{\circ} \mathrm{C}$ até $600^{\circ} \mathrm{C}$. Em poucos casos aqueceu-se os espécimens até 680 ou $700^{\circ} \mathrm{C}$. Após cada etapa de desmagnetização mediu-se novamente a magnetização remanescente. As possíveis alterações mineralógicas nas amostras que poderiam interferir na remanescência magnética foram monitoradas pelas medidas de suscetibilidade magnética realizadas, no final de cada etapa de desmagnetização, através de um medidor Bison, do tipo ponte e do equipamento SI-1 da Sapphire Instruments. Em nenhum caso verificou-se alteração significativa da suscetibilidade.

De modo geral, a maioria das amostras estudadas mostrou alta estabilidade magnética quando submetidas aos dois processos de desmagnetização o que sugere que os minerais magnéticos presentes nas amostras são capazes de reter a magnetização primária. Selecionou-se, através do diagrama de Zijderveld (1967) campos magnéticos entre 15 a $35 \mathrm{mT}$ ou temperaturas de 200 a $450^{\circ} \mathrm{C}$ para desmagnetizar pelo menos outros 2 ou 3 espécimens de uma mesma amostra. Esses campos ou temperaturas foram suficientes para eliminar magnetizações secundárias viscosas que afetam os grãos magnéticos de baixa coercitividade. Desse modo isolou-se a magnetização característica de cada espécimen. Uma descrição mais detalhada sobre o comportamento magnético das amostras estudadas pode ser encontrada em Raposo (1992).

Cerca de $7 \%$ das amostras (total de 29) foram desprezadas porque não foi possível isolar nenhuma componente de magnetização.

Mineralogia Magnética Investigou-se a mineralogia magnética das rochas, com o intuito de verificar quais são os minerais magnéticos responsáveis pela magnetização remanescente dos diques e, consequentemente, avaliar se esta magnetização é primária ou secundária.

Inicialmente fez-se um estudo em seções polidas com auxílio de microscópio polarizante com luz refletida. Identificou-se os minerais; ilmenitas, titanomagnetitas (série ulvoespinélio-magnetita $a_{\mathrm{ss}}$ ) que são mais abundantes e, pequenas quantidades de sulfetos (pirita e calcopirita).

Em todas as seções analisadas observou-se um intercrescimento de ilmenita em titanomagnetitas. Este intercrescimento origina três tipos de textura denominadas por Buddington \& Lindsley (1964) de "Trellis", "Composite" (interna e externa) e "Sandwich".

O tipo "Trellis" corresponde a uma rede ou grade de lamelas de ilmenitas em forma de ripas cruzadas as quais originam-se por oxidação a elevadas temperaturas $\left(>600^{\circ} \mathrm{C}\right)$ da série Usp-Mt

A textura "Composite" corresponde a inclusões de cristais euhedrais ou subhedrais de ilmenitas nas titanomagnetitas. Este tipo de textura pode ser dividido em "Composite" interna quando os grãos de ilmenita são totalmente inclusos nas titanomagnetitas e, "Composite" externa quando grãos ou lamelas de ilmenita são parcialmente inclusos nas titanomagnetitas ou ocorrem nas bordas das mesmas. As formas e os contatos das ilmenitas com as titanomagnetitas raramente são orientados ao longo de planos (Haggerty, 1981). Este tipo textural é menos abundante nas rochas e as ilmenitas podem ser originadas tanto por cristalização direta do líquido magmático como por oxidação.

O tipo "Sandwich" corresponde a espessas lamelas de ilmenitas na forma de ripas orientadas ao longo de planos e são relativamente comuns nas rochas. As lamelas podem ocorrer em pequenos números, no entanto, é mais comum a presença de uma única lamela na forma de ripa dentro das titanomagnetitas. Nesta textura as ilmenitas podem ser originadas diretamente do magma ou podem ser resultado da oxidação da série ulvoespinélio-magnetita ${ }_{\text {ss. }}$.

Os três tipos texturais foram encontrados na maioria das seções estudadas, embora a textura tipo "Trellis" tenha sido predominante. Este fato indica que as titanomagnetitas foram formadas a temperaturas elevadas e são, portanto, capazes de reter magnetização remanescente primária.

Foi utilizada uma balança termomagnética para investigar as temperaturas de Curie dos minerais presentes nas amostras. A figura 3 mostra exemplos, que são representativos dos diques analisados. As curvas termomagnéticas fo- 

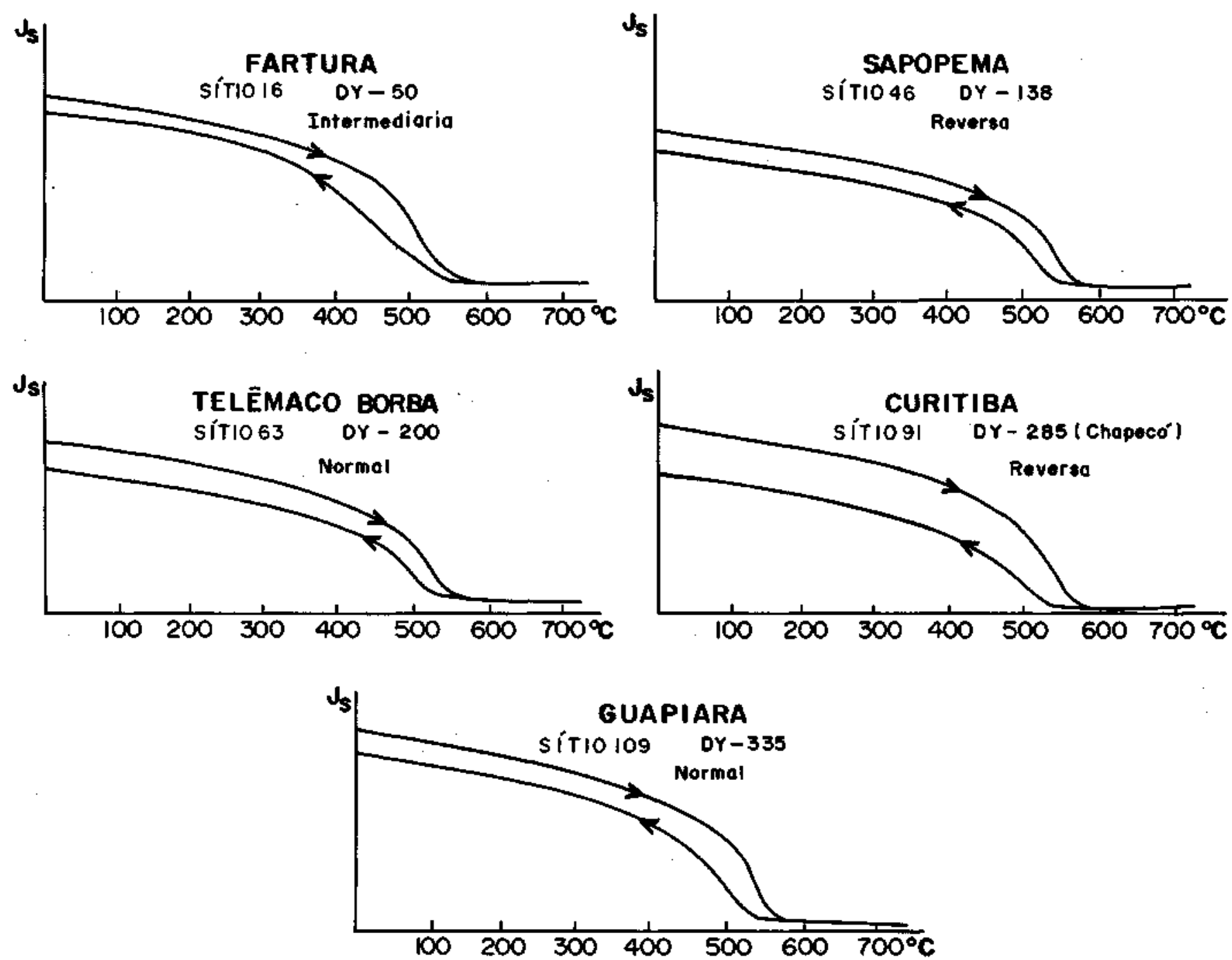

Figura 3 - Exemplos de curvas termomagnéticas dos diques aflorantes nas cinco áreas e com diferentes polaridades Figure 3 - Examples of thermomagnetic curves of the dikes from the five areas of the Ponta Grossa Arch with different polarities

ram obtidas em diques com diferentes polaridades do campo geomagnético e aflorantes nas cinco áreas onde acham-se concentrados, isto é, Fartura, Sapopema, Telêmaco Borba, Curitiba e Guapiara.

De modo geral os diques apresentaram um único valor de temperatura de Curie, que está contido no intervalo de $500-580^{\circ} \mathrm{C}$. Este intervalo mostra que os minerais magnéticos presentes nos diques são titanomagnetitas oxidadas a altas temperaturas, o que é perfeitamente concordance com os minerais identificados nas seções polidas. Isto indica que as direções de magnetização dos diques são confiáveis, isto é, devem corresponder à magnetização primária.

\section{RESULTADOS Direções Paleomagnéticas Com} o término dos trabalhos de laboratório, obteve-se a direção e a intensidade da magnetização remanescente característica (MRC) de, no mínimo, 3 espécimens medidos para cada dique (sítio) estudado. Calculou-se, então, a direção média da MRC de cada sítio e os parâmetros estatísticos de acordo com Fisher (1953), através da média das MRCs dos espécimens correspondentes. Alguns diques não deram resultados consistentes porque as amostras estavam intemperizadas e não foram capazes de reter a magnetização remanescente primária. Calculou-se, também, para cada dique o pólo geomagnético virtual (PGV) associado à direção de magnetização. Estes dados encontram-se na tabela 2 e as direções das MRCs foram representadas em um estereograma (rede) de Wulff da figura 4.

A figura 4 mostra que os diques estudados apresentam polaridade normal e reversa e que o campo geomagnético, apresentava características de campo dipolar, estas características foram comprovadas através do "teste reverso", método apresentado por McFadden \& Lowes (1981). O teste aplicado foi positivo, isto é, para o nível de confiança de 95\% a média da direções de polaridade normal não é distinta da média das direções de polaridade reversa. Algumas direções anômalas também foram registradas (sítios 5, 16, 17, 18 , 19, e 118, Tabela 2) e podem estar associadas com inversões de polaridade ou excursões geomagnéticas. Somente este fato é suficiente para afirmar que os diques do Arco de Ponta Grossa não ocorreram durante um único evento intrusivo, mas tiveram sua colocação em, pelo menos, três episódios distintos, sendo que a maioria dos corpos foram colocados quando o campo magnético terrestre apresentava polaridade normal, como é evidenciado pelo maior número de diques com essa polaridade.

Investigou-se a possibilidade das direções de magnetização estarem relacionadas com as direções estruturais dos diques. Desse modo, representou-se na Figura 5 as direções de magnetização dos diques considerando-se as orientações NW e NE. Pode ser observado que não existe uma relação entre as direções estruturais e as direções de magnetização 
Tabela 2 - Resultados paleomagnéticos dos diques do Arco de Ponta Grossa. Onde Class. =classificação, N=número de espécimens medidos, n-número de espécimens incluídos na média, Decl. $=$ declinação, Incl. $=$ inclinação, $\alpha_{95}$-raio do círculo de $95 \%$ de confiança, $R$-comprimento do vetor resultante, $k=$ parâmetro de precisão, Pol.- polaridade (N-normal, I-intermediária e R-reversa) Long.=longitude do PGV, Lat.-latitude do PGV, DM e DP-oval de 95\% de confiança,

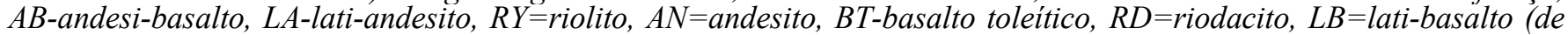
acordo com Benini,J992), S.R.S=sitios sem resultados consistentes

Table 2 - Paleomagnetic data for the Ponta Grossa dikes. Class.=classification, $\mathrm{N}=$ number of specimens per site, $\mathrm{n}=$ number of specimens included in the mean, Decl.=declination, Incl.=inclination, $\alpha_{95}=$ confidence circle of the $95 \%, \mathrm{R}=$ long of the resultant vector, $\mathrm{k}=$ precision parameter, Pol.=polarity $(\mathrm{N}=$ normal, $\mathrm{I}=$ intermediate and $\mathrm{R}=$ reverse), Lat.=latitude of the VGP, Long=longitude of the VGP, DM and DP define the $95 \%$ confidence oval for the Virtual Geomagnetic poles, LA=lati-andesite, $\mathrm{RY}=$ rhyolite, $\mathrm{AN}=$ andesite, $\mathrm{BT}=$ tholeitic basalt, $\mathrm{RD}=$ rhyodacite, $\mathrm{LB}=$ lati-basalt (according to Benini.1992), S.R.S $=$ sites without consistent results

\begin{tabular}{|c|c|c|c|c|c|c|c|c|c|c|c|c|c|}
\hline \multirow[b]{2}{*}{ SfTo } & \multirow[b]{2}{*}{ Class } & \multirow[b]{2}{*}{$\mathrm{THO}_{2}$} & \multirow[b]{2}{*}{$\mathbf{N} / \mathbf{b}$} & \multicolumn{5}{|c|}{ DIREÇAO MÉDIA DE MAGNETIZAÇĀO } & \multicolumn{5}{|c|}{ POLOS GEOMAGNETTICOS VIRTUAIS } \\
\hline & & & & $\begin{array}{c}\text { Decl. } \\
()^{\circ}\end{array}$ & $\begin{array}{l}\text { Incl. } \\
\left({ }^{\circ}\right)\end{array}$ & $\begin{array}{c}\alpha_{95} \\
\left({ }^{\circ}\right) \\
\text { FAI }\end{array}$ & URA & $\bar{k}$ & Pol. & $\begin{array}{l}\text { Long. } \\
() \mathrm{E}\end{array}$ & $\begin{array}{l}\text { Lat. } \\
\left({ }^{\circ}\right)\end{array}$ & $\begin{array}{l}\mathrm{DM} \\
(9\end{array}$ & $\begin{array}{l}D P \\
\left({ }^{\circ}\right)\end{array}$ \\
\hline 1 & $A B$ & 3,77 & $9 / 9$ & 352,3 & $-35,8$ & 2,8 & 8,977 & 341,8 & $\mathbf{N}$ & 245,5 & 82,0 & 3,2 & 1,9 \\
\hline 2 & LA & 3,09 & $8 / 8$ & 166.2 & 30,3 & 4,3 & 7,959 & 170,9 & $\mathbf{R}$ & 66.6 & $-75,2$ & 4,7 & 2,6 \\
\hline 3 & $\mathrm{AB}$ & 2,42 & $6 / 6$ & 167,7 & 40,1 & 6,2 & 5,957 & 116,5 & $\mathbf{R}$ & 41,0 & $-78,7$ & 7,5 & 4,5 \\
\hline 4 & $\mathrm{AB}$ & 2.70 & $9 / 9$ & 346,4 & $-31,8$ & 5,0 & 8,926 & 108,2 & $\mathbf{N}$ & 243,9 & 75,8 & 5,6 & 3,1 \\
\hline 5 & AN & 3,21 & $14 / 14$ & 188,2 & $-1,5$ & 2,6 & 13,945 & 234,6 & I & 149,9 & 64,6 & 2,6 & 1,3 \\
\hline 6 & $\mathbf{A B}$ & 2,59 & $9 / 9$ & 23,3 & $-63,3$ & 6,0 & 8,891 & 73,6 & $\mathbf{N}$ & 94,7 & 61,4 & 9.5 & 7,5 \\
\hline 7 & $\mathbf{R Y}$ & 1,20 & $11 / 8$ & 175,5 & 51,3 & 4,0 & 7,965 & 197,4 & $\mathbf{R}$ & 334,2 & $-80,5$ & 5,4 & 3,6 \\
\hline 8 & $\mathbf{A B}$ & 2,88 & $12 / 12$ & 348,9 & -29.8 & 2,4 & 11,967 & 331.2 & $\mathbf{N}$ & 253,4 & 77.2 & 2,6 & 1,5 \\
\hline 9 & $\mathbf{A B}$ & 3,77 & $10 / 10$ & 156,6 & 62,3 & 2,2 & 9,982 & 488,3 & $\mathbf{R}$ & 348,7 & $-62,3$ & 3,4 & 2,7 \\
\hline 10 & $\mathbf{A B}$ & 2,76 & $18 / 18$ & 15,9 & $-46,5$ & 4,4 & 17,733 & 63,7 & $\mathbf{N}$ & 59,8 & 75,2 & 5,6 & 3,6 \\
\hline 11 & $\mathbf{A B}$ & 2,83 & $9 / 6$ & 346,4 & $-34,7$ & 1,7 & 5,997 & 1472,5 & $\mathbf{N}$ & 237,4 & 76,6 & 2,0 & 1,2 \\
\hline 12 & LA & 3,57 & $22 / 19$ & 1659 & 32,6 & 3,3 & 18,829 & 105,4 & $\mathbf{R}$ & 61.7 & $-75,6$ & 3,7 & 2,1 \\
\hline 13 & L.A & 3,62 & $10 / 10$ & 164,3 & 31,4 & 2,1 & 9,984 & 550,1 & $\mathbf{R}$ & 61,4 & $.73,9$ & 2,3 & 1,3 \\
\hline 14 & $\mathbf{A B}$ & 2,38 & $6 / 6$ & 344,0 & $-37,3$ & 1,5 & 5,997 & 1967,3 & $\mathbf{N}$ & 227,0 & 75,0 & 1,8 & 1,0 \\
\hline 15 & $\mathrm{AB}$ & 2,61 & $4 / 4$ & 342,6 & $-34,1$ & 2,0 & $\mathbf{3}, 999$ & 2032,8 & $\mathbf{N}$ & 233,3 & 73,1 & 2,3 & 1,3 \\
\hline 16 & EA & 3,17 & $10 / 10$ & 167,3 & $-1,5$ & 2,4 & 9,978 & 413,1 & I & 101,6 & 62,9 & 2,4 & 1,2 \\
\hline 17 & $\mathbf{L A}$ & 3,04 & $6 / 6$ & 170,5 & $-1,2$ & 0,9 & 5,999 & 5649.7 & I & 108,1 & 64,3 & 0,9 & 0,4 \\
\hline 18 & LA & 3,16 & $9 / 9$ & 167,4 & 0,5 & 2,9 & 8,975 & 322,5 & I & 100,8 & $-63,8$ & 2,9 & 1,4 \\
\hline 19 & LA & 3,13 & $10 / 6$ & 173,4 & $-4,4$ & 4,2 & 5,981 & 261,2 & I & 115,4 & 63,6 & 4,2 & 2,1 \\
\hline 21 & $\mathbf{A B}$ & 2,79 & $18 / 18$ & 348,8 & $-29,3$ & 1.8 & 17,952 & 357,0 & $N$ & 254,8 & 76,9 & 2,0 & 1,1 \\
\hline 22 & $\mathrm{AB}$ & 2,70 & $6 / 6$ & 349,0 & $-40,7$ & 2,4 & 5,994 & 778,8 & $N$ & 219,3 & 79,9 & 2,9 & 1,8 \\
\hline 23 & $\mathrm{AB}$ & 2,45 & $6 / 6$ & 345.2 & -42.7 & 4,9 & 5,974 & 189,5 & $\mathrm{~N}$ & 211,2 & 76.4 & 6,0 & 3.7 \\
\hline 84 & $\mathrm{AB}$ & 2,45 & $9 / 9$ & 164,9 & 31,5 & 3,7 & 8,960 & 198,1 & R & 62,0 & $-74,5$ & 4,1 & 2,3 \\
\hline 119 & $\mathrm{AB}$ & 2,47 & $12 / 12$ & 4,2 & $-46,8$ & 4,5 & 11,881 & 92,2 & $\mathbf{N}$ & 90,6 & 84,3 & 5,9 & 3,8 \\
\hline 120 & $\mathrm{AB}$ & 3,77 & $9 / 9$ & 158,8 & 57,5 & 4,5 & 8,939 & 130,5 & $\mathrm{R}$ & 3569 & $-66,8$ & 6,6 & 4,9 \\
\hline 121 & $\mathbf{A B}$ & 2.77 & $15 / 15$ & 9,4 & -43.7 & $\begin{array}{c}1 ; 6 \\
\text { SAP }\end{array}$ & $\begin{array}{r}\text { J4,977 } \\
\text { РЕ М A }\end{array}$ & 599,0 & $\mathbf{N}$ & 54,5 & 81.3 & 2,0 & 1.2 \\
\hline 24 & $\mathbf{A B}$ & 2,58 & $9 / 9$ & 349,4 & $-37,8$ & 2,6 & 8.979 & 382.8 & $\mathbf{N}$ & 233.3 & 79,8 & 3,1 & 1,8 \\
\hline 25 & $\mathbf{A B}$ & 2,78 & $9 / 9$ & 344,6 & $-36,3$ & 4,8 & 8,930 & 115,0 & $\mathbf{N}$ & 231,5 & 75,2 & 5,6 & 3,3 \\
\hline 26 & AN & 3,67 & - & - & - & -- & $\ldots$ & - & S.R.C. & -- &. & - & .- \\
\hline 27 & AN & 2,82 & $9 / 6$ & 354,5 & $-44,7$ & 2,3 & 5,994 & 856.8 & $\mathbf{N}$ & 193,7 & 84,5 & 2,9 & 1,8 \\
\hline 28 & LA & 3,12 & $21 / 21$ & 353,8 & $-42,7$ & 1,8 & 20,940 & 331.5 & $\mathbf{N}$ & 210,7 & 84,3 & 2,2 & 1,3 \\
\hline 29 & LA & 3,12 & $6 / 6$ & 5,9 & $-31,4$ & 2,3 & 5,994 & 847,4 & $\mathrm{~N}$ & 348,4 & 81,1 & 2,6 & 1,4 \\
\hline 30 & LA & 3,19 & $14 / 14$ & 355,4 & $-50,6$ & 8,0 & 13,491 & 25,5 & $N$ & 157,4 & 81,5 & 10,8 & 7,3 \\
\hline 31 & $\mathrm{AB}$ & 3,65 & $12 / 12$ & 10,2 & $-26,5$ & 5,0 & 11,856 & 76,2 & $\mathbf{N}$ & 355,9 & 76,3 & 5,4 & 2,9 \\
\hline 32 & LA & 2.91 & $10 / 10$ & 350.5 & -29.1 & 2,8 & 9.970 & 304.4 & $\mathbf{N}$ & 260.1 & 77.9 & 3,1 & 1,7 \\
\hline 33 & LA & 2,76 & $9 / 9$ & 356,9 & $-34,3$ & 3,9 & 8,954 & 174,2 & $\mathbf{N}$ & 278,0 & 84,3 & 4,5 & 2,6 \\
\hline 34 & $\mathrm{AB}$ & 3,03 & $10 / 10$ & 352,2 & $-33,4$ & 4,6 & 9,919 & 110,9 & $\mathbf{N}$ & 255,1 & 80,9 & 5.2 & 3,0 \\
\hline 35 & $\mathbf{A B}$ & 2,62 & $9 / 9$ & 339,2 & $-28,0$ & 8,1 & 8,805 & 41,0 & $\mathbf{N}$ & 240,0 & 68.5 & 8.9 & 4,9 \\
\hline 46 & LA & 2,68 & $6 / 6$ & 176,4 & 58,7 & 6,0 & 5,960 & 126,5 & $\mathrm{R}$ & 320,4 & $-74,7$ & 8,9 & 6,6 \\
\hline 47 & - & - & $9 / 9$ & 355,4 & $-52,8$ & 3,3 & 8,968 & 247,9 & N & 153,6 & 80,4 & 4,5 & 3,1 \\
\hline 52 & $\mathbf{A B}$ & 2,28 & $11 / 11$ & 347,8 & $-42,2$ & 3,1 & 10.953 & 213.2 & $\mathrm{~N}$ & 217.8 & 78,9 & 3,9 & 2,4 \\
\hline & & & & & & $E \mathrm{MA}$ & O B O & & & & & & \\
\hline 36 & $\mathrm{AB}$ & 2,92 & $16 / 11$ & 354,5 & $-35,0$ & 1,5 & 10,989 & 873,2 & $\mathbf{N}$ & 260,9 & 83,0 & 1,8 & 1,0 \\
\hline 37 & $\mathrm{AB}$ & 2,57 & $9 / 9$ & 181,2 & 51,0 & 4,7 & 8,934 & 121,0 & $\mathbf{R}$ & 301,2 & $-82,3$ & 6,4 & 4,3 \\
\hline 38 & LA & 2,54 & $6 / 6$ & 334,8 & $-40,5$ & 10,3 & 5,885 & 43,4 & $\mathbf{N}$ & 216,0 & 66.9 & 12.5 & 7,5 \\
\hline 39 & $\mathbf{A B}$ & 2,83 & $9 / 6$ & 154,4 & 56,1 & 2,0 & 5,996 & 1150,6 & R & $\mathbf{3 , 3}$ & $-64,7$ & 2,8 & 2,0 \\
\hline $40^{\circ}$ & $\omega$ & $=$ & $3 / 3$ & 3,5 & $-\$ 2,9$ & 4,5 & 2,997 & 757,2 & $\mathbf{N}$ & 111,4 & 80.2 & 6,2 & 4,3 \\
\hline A1 & $\mathbf{A B}$ & 2,93 & $6 / 6$ & 3,4 & -39.1 & 3,3 & 5,988 & 404.7 & $\mathbf{N}$ & 4.9 & 86,1 & 4,0 & 2,4 \\
\hline 42 & AN & 3,28 & $10 / 10$ & 2,9 & $-33,8$ & 4,5 & 9,924 & 118,8 & $\mathrm{~N}$ & 334.7 & 83,5 & 5,1 & 2,9 \\
\hline 43 & AN & 2,65 & $9 / 9$ & 353,0 & $-43,1$ & 2,7 & 8,979 & 372,3 & $\mathbf{N}$ & 211,7 & 83,6 & 3,3 & 2,1 \\
\hline 44 & LA & 3.29 & $10 / 10$ & 341.8 & $-21,0$ & 3.1 & 9.963 & 246.0 & $\mathbf{N}$ & 254,0 & 68.1 & 3,2 & 1,7 \\
\hline 45 & $\mathrm{AB}$ & 3,26 & $7 / 7$ & 160,1 & 57,3 & 2,4 & 6,990 & 620,8 & $\mathrm{R}$ & 356,4 & $-68,4$ & 3,5 & 2,6 \\
\hline 49 & $\mathrm{AB}$ & 2,38 & $9 / 9$ & 156,1 & 57,5 & 5,2 & 8,919 & 99,0 & $R$ & 0.1 & $-65,6$ & 7,6 & 5,6 \\
\hline 50 & $\mathbf{L A}$ & 3,01 & $6 / 6$ & 10,1 & $-40,6$ & 2,7 & 5,992 & 598,0 & $N$ & 31,7 & 80,6 & 3,3 & 2.0 \\
\hline 51 & $\mathbf{A B}$ & 2,46 & $8 / 8$ & 0,5 & $-41,2$ & 3,3 & 7,976 & 286,9 & $\mathbf{N}$ & 330,9 & 88,8 & 4,0 & 2,4 \\
\hline 53 & $A N$ & 2,10 & $9 / 9$ & 357,7 & $-29,0$ & 2,6 & $8,980^{\circ}$ & 402,8 & $\mathbf{N}$ & 294,6 & 81,3 & 2,8 & 1,6 \\
\hline 54 & $\mathrm{AB}$ & 2,38 & $9 / 9$ & 331,1 & $-57,5$ & 2,2 & 8,986 & 568,9 & $\mathbf{N}$ & 182,7 & 61.8 & 3.2 & 2,3 \\
\hline 55 & AN & 1,48 & $11 / 11$ & 4,3 & $-48,2$ & 6.4 & 10,809 & 52,5 & $N$ & 92,0 & 83,7 & 8,3 & 5,5 \\
\hline
\end{tabular}


Tabela 2 (continuação)

Tabela 2 (continuation)

\begin{tabular}{|c|c|c|c|c|c|c|c|c|c|c|c|c|c|}
\hline \multirow[b]{2}{*}{ sftio } & \multirow[b]{2}{*}{ Class } & \multirow[b]{2}{*}{$\mathrm{TiO}_{2}$} & \multirow[b]{2}{*}{$N / \mathbf{n}$} & \multicolumn{5}{|c|}{ DIREÇ̄o MÉDIA DE MAGNETIZAÇĀO } & Pól & $S$ GEOH & GNETI & S VIRT & \\
\hline & & & & $\begin{array}{c}\text { Decl. } \\
\left({ }^{\circ}\right)\end{array}$ & $\begin{array}{c}\text { Jncl. } \\
\left({ }^{\circ}\right)\end{array}$ & $\begin{array}{l}a_{95} \\
(9)\end{array}$ & $\mathbf{R}$ & k & Pol. & $\begin{array}{l}\text { Long. } \\
\text { ( } 9 \mathrm{E}\end{array}$ & $\begin{array}{l}\text { Lat } \\
(9)\end{array}$ & $\begin{array}{c}\mathrm{DM} \\
()^{\circ}\end{array}$ & $\begin{array}{l}\mathrm{DP} \\
(9)\end{array}$ \\
\hline 56 & $\mathbf{A B}$ & 2,12 & $8 / 6$ & 347,3 & $-46,6$ & 2,5 & 5,993 & 701,1 & $\mathbf{N}$ & 200,9 & 78,2 & 3,3 & 2,1 \\
\hline 57 & $A B$ & 3,31 & $6 / 6$ & 341,6 & $-58,0$ & 3,8 & 5,984 & 311,9 & $\mathbf{N}$ & 172,7 & 69,0 & 5,6 & 4,1 \\
\hline 58 & AN & 2,54 & 77 & 147.9 & 46,7 & 9,3 & 6,862 & 43,5 & $\mathbf{R}$ & 24,9 & $-61,1$ & 11,9 & 7,7 \\
\hline 59 & LA & 3,45 & $9 / 9$ & 192,7 & 21,7 & 1,3 & 8,995 & 1460,2 & $\mathbf{R}$ & 173,0 & $-72,0$ & 1,4 & 0,8 \\
\hline 60 & $\mathrm{AB}$ & 4,07 & $9 / 9$ & 359,5 & $-38,2$ & 1,5 & 8,993 & 1123,0 & $\mathbf{N}$ & 299,8 & 86,9 & 1,8 & 1,1 \\
\hline 61 & BT & 1,15 & $9 / 9$ & 359.7 & $-56,7$ & 1,8 & 8,990 & 807,4 & $\mathbf{N}$ & 129,3 & 77,2 & 2,6 & 1,9 \\
\hline 62 & $\mathrm{AB}$ & 1,89 & $56 / 43$ & 186,8 & 39.5 & 1,7 & 42,749 & 167,6 & $\mathbf{R}$ & 202,3 & $-83,4$ & 2,0 & 1,2 \\
\hline 63 & - & $=$ & $3 / 3$ & 2,0 & $-54,2$ & 2,2 & 2,999 & 3221,4 & $\mathbf{N}$ & 120,2 & 79,7 & 3,1 & 2,1 \\
\hline 64 & $\mathbf{A B}$ & 2,30 & $8 / 8$ & 358,0 & -50.7 & 5,6 & 7,930 & 100,6 & $\mathbf{N}$ & 143,0 & 82,9 & 7,5 & 5,0 \\
\hline 65 & AB & 2,54 & $9 / 9$ & 161,9 & 45.4 & 1.8 & 8,990 & 826.4 & $\mathbf{R}$ & 27,5 & .73 .6 & 2,3 & 1.4 \\
\hline 66 & AN & 2,43 & $9 / 9$ & 357,5 & $-35,0$ & 4,0 & 8.952 & 166.5 & $\mathbf{N}$ & 285,1 & 84,2 & 4,6 & 2,7 \\
\hline 67 & AB & 2,09 & $9 / 9$ & 335,3 & $-37,4$ & 8.3 & 8.797 & 39,4 & $\mathbf{N}$ & 223,6 & 67,0 & 9,8 & 5,7 \\
\hline 68 & $A B$ & 2,93 & $9 / 9$ & 358,5 & $-40,6$ & 1,0 & 8,997 & 2719,2 & $\mathbf{N}$ & 266.4 & 87.9 & 1,2 & 0.7 \\
\hline 69 & $A B$ & 2,70 & $9 / 9$ & 4,2 & $-33,4$ & 2,4 & 8,982 & 453,0 & $\mathbf{N}$ & 341,6 & 82,5 & 2,8 & 1,6 \\
\hline 70 & $\mathrm{AB}$ & 2,63 & $9 / 9$ & 357,6 & $-43,4$ & 1,5 & 8,993 & 1151,6 & $\mathbf{N}$ & 203,8 & 87.7 & 1,9 & 1,2 \\
\hline 71 & $\mathrm{AB}$ & 2,41 & $12 / 12$ & 353,3 & $-36,6$ & 2,1 & 11,975 & 439,2 & $\mathbf{N}$ & 253,3 & 82,5 & 2,4 & 1,4 \\
\hline & & & & & & $\mathrm{CU}$ & [IBA & & & & & & \\
\hline 72 & AB & 2,1 & $6 / 3$ & 335,8 & $-28,1$ & 4,4 & 2,997 & 780,9 & $\mathbf{N}$ & 239,4 & 65,2 & 4,8 & 2,7 \\
\hline 73 & LA & 2,85 & - & - & $=$ & $\because$ & $\because$ & 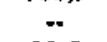 & S.R.C. & $=$ & $\because$ & 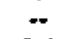 & - \\
\hline 74 & LA & 2,89 & $12 / 12$ & 345.1 & $-33,3$ & 8.0 & 11,640 & 30.5 & $\mathbf{N}$ & 243.8 & 74,6 & 9.1 & 5.2 \\
\hline 75 & L.A & 3,03 & $9 / 9$ & 0,5 & $-51,4$ & 2,2 & 8,985 & 533,8 & $\mathbf{N}$ & 126.7 & 83,0 & 3.0 & 2.1 \\
\hline 76 & $\mathbf{B T}$ & 1.51 & $6 / 6$ & 0,3 & -35.2 & 3,2 & 5,988 & 430,7 & $\mathrm{~N}$ & 313,3 & 84,3 & 3.7 & 2.2 \\
\hline 77 & $\mathrm{AB}$ & 2,50 & $9 / 9$ & 160,6 & 54,2 & 2,2 & 8,986 & 561,3 & $\mathbf{R}$ & 6,1 & $-70,7$ & 3,1 & 2,1 \\
\hline 78 & $A B$ & 2,21 & $6 / 6$ & 341,8 & $-42,0$ & 5,7 & 5,965 & 141,4 & $\mathbf{N}$ & 219,6 & 73,5 & 6,9 & 4,3 \\
\hline 79 & $\mathbf{A B}$ & 2,11 & $9 / 9$ & 154,0 & 37,6 & 4,7 & 8,935 & 123,6 & $\mathbf{R}$ & 46.4 & $.65,8$ & 5,5 & 3,2 \\
\hline $79^{\circ}$ & BT & 1,77 & $6 / 6$ & 351,0 & $-38,2$ & 2,2 & 5,995 & 930,2 & $\mathbf{N}$ & 245.7 & 80,7 & 2,6 & 1,5 \\
\hline 80 & $A B$ & 2,44 & $9 / 9$ & 357,6 & $-42,8$ & 2,6 & 8,980 & 405,8 & $\mathbf{N}$ & 239,3 & 87.7 & 3.2 & 2,0 \\
\hline 81 & $\mathrm{AB}$ & 2,49 & $6 / 6$ & 165,0 & 46,3 & 2,7 & 5,992 & 617,7 & R & 29,2 & $-76,4$ & 3,5 & 2,2 \\
\hline 82 & $\mathrm{BT}$ & 1,77 & $12 / 12$ & 349,8 & $-32,1$ & 2,7 & 1,957 & 253,7 & $\mathbf{N}$ & 259.7 & 77,6 & 3.1 & 1,7 \\
\hline 83 & $\mathbf{A B}$ & 3,45 & $12 / 12$ & 181,2 & 45,2 & 1,7 & 11,984 & 691,1 & $\mathbf{R}$ & 273,6 & $-88,2$ & 2,1 & 1,3 \\
\hline 85 & LA & 1,29 & $16 / 16$ & 354,4 & $-58,0$ & 3,9 & 15,835 & 90,9 & $\mathbf{N}$ & 149,1 & 75.7 & 5.7 & 4,2 \\
\hline 86 & $\mathrm{AB}$ & 3,48 & $6 / 6$ & 171,2 & 45,0 & 4,8 & 5,975 & 197,2 & $\mathbf{R}$ & 29,6 & $.81,9$ & 6,1 & 3,8 \\
\hline 87 & RY & 1,41 & $5 / 5$ & 181.1 & 46.2 & 4,5 & 4,986 & 293.1 & $\mathbf{R}$ & 289.4 & $-87,4$ & 5.7 & 3,7 \\
\hline 88 & RD & 0.42 & - & $=$ & -- & $=$ & 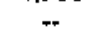 & - & S.R.C. & $\cdots$ & $\cdots$ & - & $=$ \\
\hline 89 & $\mathbf{A B}$ & 2,32 & $=$ & $=$ & -. & $=$ & -. & -- & S.R.C. & -. & -. & - & $=$ \\
\hline 90 & LA & 3,18 & $5 / 5$ & 174,4 & 44,2 & 2,4 & 4,996 & 1017,8 & $\mathbf{R}$ & 29,4 & $.84,9$ & 3,0 & 1,9 \\
\hline 91 & $\overrightarrow{R Y}$ & 1,40 & $12 / 12$ & 168,5 & 44,5 & 1,6 & 11,985 & 723,9 & $\mathrm{R}$ & 32,1 & $-79,6$ & 2,0 & 1.3 \\
\hline 92 & LB & 2,42 & $3 / 3$ & 180,4 & 37,3 & 1,9 & 3,000 & 4454,9 & $\mathrm{R}$ & 135,9 & $-85,8$ & 2,2 & 1,3 \\
\hline 93 & BT & 1,08 & $6 / 6$ & 346,4 & $-34,0$ & 3,9 & 5,983 & 301,7 & $\mathrm{~N}$ & 245,0 & 75,8 & 4,4 & 2,5 \\
\hline 94 & $\mathrm{AB}$ & 2,44 & $6 / 6$ & 164,7 & 48,9 & 2,7 & 5,992 & 633,8 & $\mathbf{R}$ & 18,6 & $-75,7$ & 3,5 & 2,3 \\
\hline 95 & LA & 3,72 & $9 / 9$ & 161,6 & 33,4 & 2,3 & 8,984 & 509,7 & $\mathrm{R}$ & 59,1 & $-71,6$ & 2,6 & 1,5 \\
\hline 96 & $\mathrm{AB}$ & 2.75 & $12 / 12$ & 353,0 & $-54,6$ & 2.1 & 11975 & 444,6 & $\mathbf{N}$ & 160,9 & 78,4 & 2,9 & 2,1 \\
\hline 97 & $\mathrm{AB}$ & 2,57 & $4 / 4$ & 351,4 & -33.1 & 7,2 & 3,982 & 163.7 & $\mathbf{N}$ & 170.6 & 78.8 & 10,0 & 6.9 \\
\hline 98 & $\mathrm{AB}$ & 2,04 & $5 / 5$ & 192,3 & 41,6 & 4,7 & 4,985 & 270,4 & $\mathbf{R}$ & 216,5 & $-78,8$ & 5,7 & 3.5 \\
\hline 99 & $\mathrm{AB}$ & 1,91 & $9 / 9$ & 344,3 & $-33,7$ & 1,6 & 8,993 & 1084,5 & $\mathbf{N}$ & 242,9 & 73,9 & 1,8 & 1,0 \\
\hline 100 & AN & 1,39 & $7 / 7$ & 11,1 & $-54,7$ & 7,1 & 6,917 & 72,5 & $N$ & 89,3 & 76,3 & 10,1 & 7,1 \\
\hline 101 & AN & 1,86 & $11 / 11$ & 343,0 & $.49,4$ & 3,0 & 10,956 & 229,3 & $\mathrm{~N}$ & 199.0 & 74,3 & 4,0 & 2,7 \\
\hline 102 & $\mathbf{A B}$ & 2,74 & $6 / 6$ & 349.6 & $-51,1$ & 1,5 & 5,998 & 2098,8 & $\mathrm{~N}$ & 183,0 & 78,8 & 2,0 & 1,3 \\
\hline 103 & $\mathbf{A B}$ & 2.10 & $4 / 4$ & 154.6 & 28.5 & 3.8 & 3.995 & 581.1 & $\mathrm{R}$ & 58.8 & .64 .2 & 4,2 & 2,3 \\
\hline 104 & LB & 2,00 & $27 / 27$ & 358,4 & $-46,0$ & 1,9 & 26.881 & 218.9 & $\mathrm{~N}$ & 158.7 & 8699 & 2.4 & 1.5 \\
\hline 122 & BT & 1,39 & $9 / 9$ & 355,8 & $-54,1$ & 1,4 & 8,994 & 1404,9 & $\mathbf{N}$ & 132,4 & 80,4 & 1,9 & 1,4 \\
\hline 123 & BT & 1,35 & $6 / 6$ & 348,4 & $-53,1$ & 2,1 & 5,995 & 1066,3 & $\mathbf{N}$ & 180,3 & 77,2 & 2,8 & 2,0 \\
\hline & & & & & & GU & IARA & & & & & & \\
\hline 105 & $\mathrm{AB}$ & 2,69 & $12 / 12$ & 165,8 & 34,8 & 1,8 & 11,981 & 564,5 & $\mathbf{R}$ & 62,9 & $-75,6$ & 2,1 & 1,2 \\
\hline 106 & $\mathrm{AB}$ & 2,63 & $8 / 4$ & 336,6 & $.39,8$ & 8,4 & 3,975 & 120,4 & $\mathrm{~N}$ & 220,8 & 68.5 & 10.1 & 6.1 \\
\hline 107 & $\mathrm{AB}$ & 2,08 & $9 / 6$ & 345,1 & -49.8 & 1,6 & 5,997 & 1802,3 & $\mathrm{~N}$ & 192,4 & 75,3 & 2,1 & 1,4 \\
\hline 108 & $\mathrm{AB}$ & 2,41 & $3 / 3$ & 352,4 & $-32,8$ & 1.4 & 3,000 & 7810.6 & $\mathrm{~N}$ & 261.7 & 80.4 & 1,6 & 0.9 \\
\hline 109 & $\mathrm{AB}$ & 2.04 & $9 / 9$ & 354.9 & $-34,8$ & 1.3 & 8.995 & 1522,2 & $\mathbf{N}$ & 267,3 & 83.1 & 1,5 & 0,9 \\
\hline 110 & LA & 2,51 & $3 / 3$ & 1,0 & $-39,0$ & 15.1 & 2,971 & 68.1 & $\mathbf{N}$ & 334,7 & 87,6 & 18,0 & 10,7 \\
\hline 111 & LA & 2,27 & $10 / 6$ & 1,7 & $-24,9$ & 11,4 & 5,859 & 35,4 & $\mathbf{N}$ & 320,0 & 78,8 & 12,3 & 6,6 \\
\hline 112 & LA & 2,61 & $7 / 7$ & 358,3 & $-28,0$ & 4,6 & 6,966 & 174.2 & $\mathbf{N}$ & 301,5 & 80,6 & 5,0 & 2,8 \\
\hline 113 & LA & 3,49 & $9 / 9$ & 171,8 & 52,8 & 3,5 & 8,963 & 219,0 & $\mathbf{R}$ & 347,3 & $-78,3$ & 4,8 & 3,3 \\
\hline 114 & $\overline{A N}$ & 3,10 & $12 / 12$ & 196,2 & 32,3 & 6,9 & 11,728 & 40,5 & $\mathrm{R}$ & 200,3 & $-73,4$ & 7,8 & 4,4 \\
\hline 115 & $\mathrm{AB}$ & 2,78 & 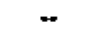 & - & $=$ & -. & - & - & S.R.C. & 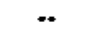 & -* & - & - \\
\hline 116 & LB & 1.38 & - & - & - & $=$ & $*$ & - & S.R.C. & -- & -. & -- & - \\
\hline 117 & $\mathrm{BT}$ & 1,44 & $4 / 4$ & 340,0 & $-49,9$ & 3,1 & 3,997 & 878,4 & $\mathbf{N}$ & 196,7 & 71.1 & 4,1 & 2,8 \\
\hline 118 & LA & 3,59 & $12 / 8$ & 174,1 & -4.1 & 15,9 & 7,464 & 13,1 & I & 118.1 & 63.1 & 16.0 & 8.0 \\
\hline 131 & LA & 2,96 & $9 / 9$ & 164,0 & 55.7 & 2,3 & 8,984 & 516,1 & R & 355,0 & $-71,5$ & 3,3 & 2,3 \\
\hline 132 & LA & 3,47 & $9 / 9$ & 165,0 & 51,0 & 2,1 & 8,987 & 612,1 & $\mathrm{R}$ & 10,3 & $-75,0$ & 2,8 & 1,9 \\
\hline 133 & $\mathbf{A B}$ & 2,40 & $6 / 6$ & 352,6 & $-49,2$ & 0,8 & 5,999 & 7297,0 & $\mathbf{N}$ & 179,0 & 81,4 & 1,0 & 0.7 \\
\hline 1,34 & $\mathbf{A B}$ & 2,63 & $3 / 3$ & 345,3 & $-43,0$ & 5,4 & 2,996 & 519,6 & $\mathbf{N}$ & 216,4 & 76,7 & 6,7 & 4,2 \\
\hline 135 & AB & 2,43 & $8 / 5$ & 144,9 & 51,3 & 3,6 & 4,991 & 457,9 & $\mathbf{R}$ & 19,6 & $-58,4$ & 4,9 & 3,3 \\
\hline
\end{tabular}




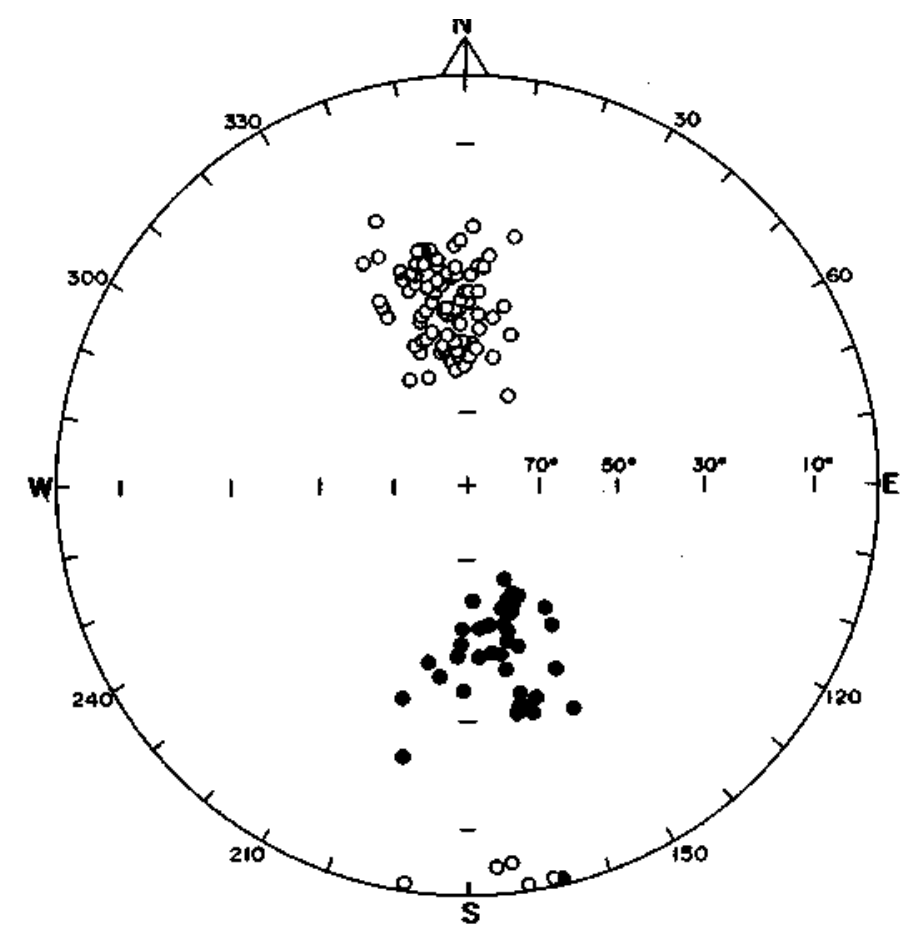

Figura 4 - Direções médias de magnetização de 121 diques do Arco de Ponta Grossa estudados. Os símbolos vazios representam polaridade normal e os cheios polaridade reversa do campo geomagnético. Os pontos na borda da rede correspondem às direções intermediárias (anômalas) Figure 4 - Mean magnetization directions for 121 studied dikes from Ponta Grossa Arch. Open and solid symbols correspond to normal and reverse polarities of the geomagnetic field, respectively. The symbols near to border of the stereogram are intermediate (anômala) directions

dos diques, ou seja, nas duas orientações ocorrem diques com polaridades normal e reversa. Isto sugere que as fraturas foram indistintamente preenchidas durante os episódios intrusivos que ocorreram no Arco de Ponta Grossa.

Análise e Cojnparação dos Dados Paleomagnéticos por Ârea de Maior Concentração dos Diques Uma vez que os dados paleomagnéticos obtidos (Fig. 4) sugeriram que a colocação dos diques ocorreu em fases ou episódios intrusivos distintos, representou-se separadamente em estereogramas de Wulff (Fig. 6), as direções de magnetização dos diques aflorantes nas cinco áreas do Arco de Ponta Grossa (Fartura, Sapopema, Telêmaco Borba, Curitiba e Guapiara). Este procedimento teve por objetivo verificar possíveis diferenças nas direções de magnetização dos diques que ocorrem na mesma área, assim como também verificar possíveis diferenças paleomagnéticas entre as áreas.

Observa-se na Fig. 6 que nas cinco áreas afloram diques com polaridades normal e reversa do campo geomagnético. Entretanto, há diferenças significativas nas direções paleomagnéticas dos diques pertencentes a uma mesma área, dentro desses intervalos de polaridade. Este fato sugere que os diques não foram colocados ou, pelo menos, não adquiriram sua magnetização remanescente, contemporaneamente dentro de uma mesma área e, portanto, episódios distintos devem ter ocorrido dentro de cada uma delas.

De modo geral, quando o campo geomagnético apresentava polaridade reversa ocorreu atividade intrusiva em todas as áreas do Arco, entretanto, na área de Curitiba (Fig. 6D) esta atividade parece ter sido mais intensa como é evidenciado pelo maior número de diques $(44 \%)$ com essa polaridade, enquanto que na área de Sapopema (Fig. 6B) não foi muito expressiva, pois, há somente um registro.

As direções intermediárias (anômalas) típicas de inversão ou excursão do campo geomagnético, somente foram identificadas nas áreas de Fartura (Fig. 6A) e Guapiara (Fig. 6E), sugerindo que apenas estas duas áreas deveriam estar ativas durante esse período.

$\mathrm{Na}$ tentativa de verificar se houveram episódios intrusivos coincidentes entre as cinco áreas do Arco de Ponta Grossa, inicialmente dividiu-se cada área em grupos de direções de magnetização. Estes grupos eram bastante evidentes em Fartura (Fig. 6A), Curitiba (Fig. 6D) e Guapiara (Fig. 6E). Nas áreas de Sapopema (Fig. 6B) e Telêmaco Borba (Fig. 6C), procurou-se agrupar as direções considerando, principalmente, as diferenças nas inclinações, a exemplo dos grupos existentes nas demais áreas.

Efetuou-se médias das direções de magnetização dos sítios pertencentes a cada grupo determinado. Estas médias encontram-se nas Tabelas de 3 a 7 e foram representadas com seus respectivos círculos de $95 \%$ de confiança (0X95) na Fig.7. Algumas direções foram representadas considerando-se apenas um dique, o qual foi designado por seu número de campo e cujos dados estão na Tabela 2 , e correspodem aos números 5, 6, 16, 17, 18 e 19 em Fartura (Fig. 7A). Neste caso em particular os círculos de confiança $\left(\alpha_{95}\right)$ não foram representados na figura porque estes diques apresentam direção magnética anômala (borda da rede), $46 \mathrm{em}$ Sapopema (Fig. 7B), 44, 59 e 62 em Telêmaco Borba (Fig. 7C), 72 e 77 em Curitiba (Fig. 7D) e 105,114 e 118 em Guapiara (Fig. 7E). Procedeu-se desse modo com o intuito de verificar se estes diques encontravam correspondências entre si.

Como cada área apresenta pelo menos dois grupos de direções médias de magnetização nos intervalos de polaridade, representou-se todos estes grupos de direções, juntamente com seus respectivos círculos de $95 \%$ de confiança (095), na Figura 8, para visualizar melhor aqueles que deveriam ser comparados. Nesta figura as direções médias dos grupos foram representadas com símbolos diferentes para cada área.

Um critério bastante simples que pode ser empregado para investigar se direções de magnetização são iguais ou diferentes consiste em verificar se há um entrelaçamento dos círculos de $95 \%$ de confiança («95) das médias a serem comparadas. Se estes círculos não se interceptam então as direções, seguramente, são diferentes, entretanto, se eles se entrelaçam então, a hipótese de que as direções possam ser iguais ou diferentes não pode ser descartada ao nível de $95 \%$ de confiança. Neste caso é necessário que testes estatísticos mais elaborados sejam aplicados.

Pode ser visto na Figura 8 que os círculos de 95\% de confiança de algumas direções médias das cinco áreas não se interceptam e que as direções correspondentes aos sítios $6,44,59,62,72$ e 114 encontram-se afastados das direções médias principais e, por isso, não serão considerados nesta abordagem. Observa-se também, que há muitas sobreposições entre os círculos de confiança das diferentes direções médias de todas as áreas. Nestes casos aplicou-se o teste estatístico de distribuição F de McFadden \& Lowes (1981), para verificar a igualdade das direções médias de magnetização.

O resultado do teste $\mathrm{F}$ revelou que há $95 \%$ de probabilidade de igualdade para as direções médias das áreas de Curitiba $\left(\mathrm{C}_{2}\right)$ e Telêmaco Borba $\left(\mathrm{T}_{2}\right)$ (ver Figura 7 para identificação das direções médias); Guapiara $\left(\mathrm{G}_{2}\right)$ e Sapopema $\left(\mathrm{S}_{2}\right)$; Curitiba $\left(\mathrm{C}_{1}\right)$ e Fartura $(\mathrm{F}$,$) ; Guapiara \left(\mathrm{G}_{1}\right)$, Sapopema $\left(\mathrm{S}_{1}\right)$ e Telêmaco Borba $\left(\mathrm{T}_{1}\right)$, para a polaridade normal do campo geomagnético. 


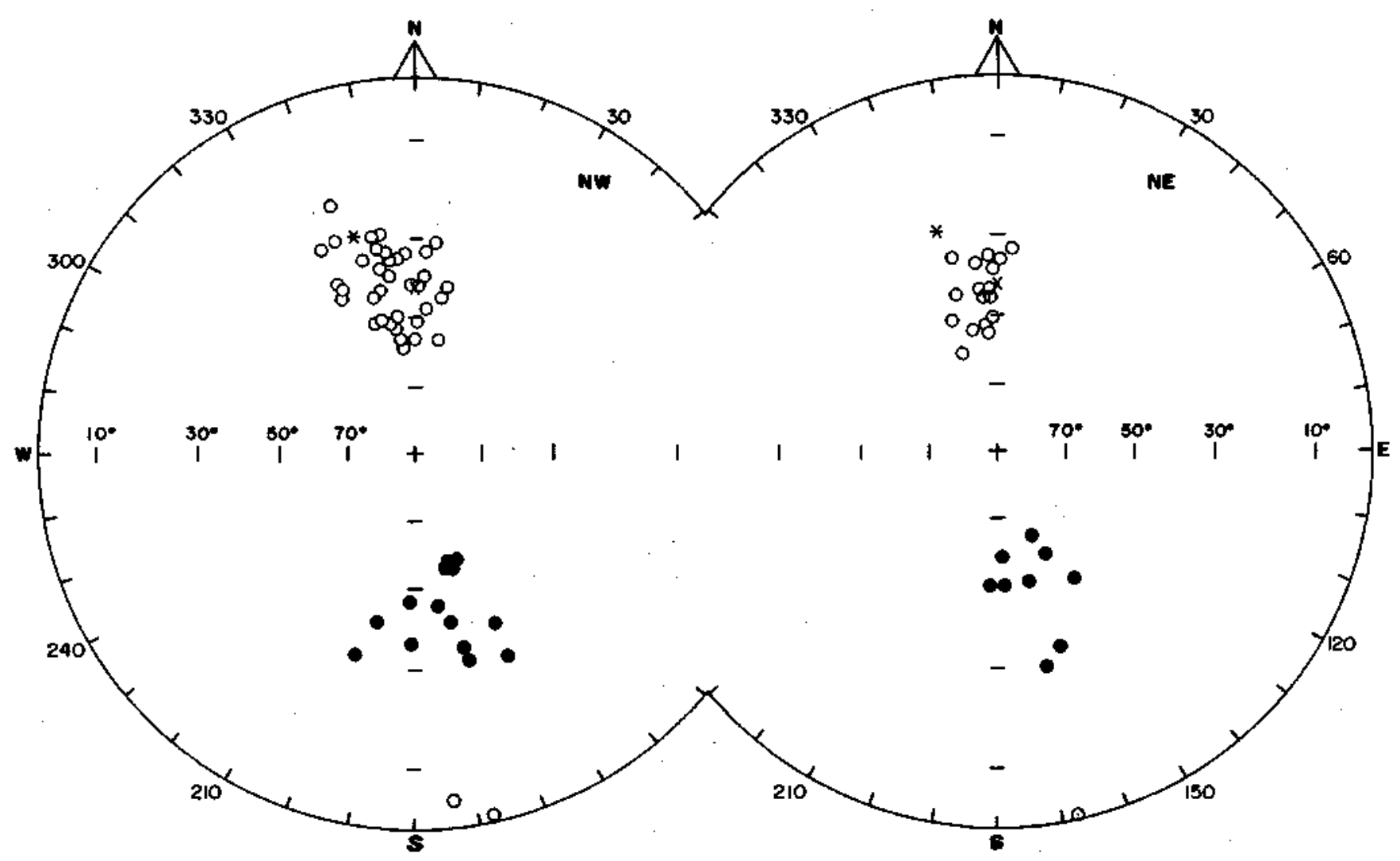

Figura 5 - Direções médias de magnetização dos diques do Arco de Ponta Grossa com trends NW e NE. Símbolos vazios representam polaridade normal e os cheios polaridade reversa do campo geomagnético. * e x correspondem, respectivamente, aos campo geomagnético atual e campo geomagnético dipolar

Figure 5 - Mean magnetization directions of the NW and NE trending dikes from Ponta Grossa dikes. Open and solid symbols are normal and reverse polarities of the geomagnetic field. * and $\mathrm{x}$ correspond to present and dipolar geomagnetic field, respectively

Tabela 3 - Médias das direções de magnetização remanescente característica dos diques da região de Fartura. Estas médias encontram-se representadas na Fig. 7 A. Onde Médias indica a posição na rede, $N=$ total de sítios incluídos na média, os demais símbolos são os mesmos da Tabela 2 Table 3 - Mean characteristic remanent magnetization directions of the dikes from Fartura region. These mean are represented in Fig. 7A. Médias indicates the position on the stereonet, $\mathrm{N}=$ sites included in the mean, the other symbols are as in Table 2

\begin{tabular}{|c|c|c|c|c|c|c|c|}
\hline Medias & $\begin{array}{c}\text { Decl. } \\
(9\end{array}$ & $\begin{array}{l}\text { Incl. } \\
\left({ }^{\circ}\right)\end{array}$ & $\begin{array}{l}095 \\
(0)\end{array}$ & $\mathbf{k}$ & $\mathbf{R}$ & $\mathbf{N}$ & Sítios \\
\hline$F_{1}$ & 347,1 & $.35,2$ & 3,3 & 243,72 & 8.96718 & 9 & $\begin{array}{r}1,4,8,11,14 \\
15,21,22,23\end{array}$ \\
\hline$F_{2}$ & 9,8 & $-45,7$ & 6.7 & 338.9 & 2,99410 & 3 & $10,119,121$ \\
\hline$F_{3}$ & 164,6 & 57,3 & 12,1 & 103,5 & 2,98068 & 3 & $7,9,120$ \\
\hline $\mathbf{F}_{4}$ & 165,8 & 33,2 & 3,8 & 394,4 & 4,98986 & 5 & $2,3,12,13,84$ \\
\hline 6 & 23,3 & $-63,3$ & 6,0 & 73,6 & 8,891 & - & $\begin{array}{l}\text { 6-dados da } \\
\text { Tabela } 2\end{array}$ \\
\hline
\end{tabular}

Para a polaridade reversa do campo geomagnético o teste $\mathrm{F}$ mostrou igualdade das direções médias entre as áreas: Telêmaco Borba $\left(\mathrm{T}_{3}\right),>$ Sapopema $(46)$, Fartura $\left(\mathrm{F}_{3}\right)$, Curitiba (77) e Guapiara $\left(\mathrm{G}_{3}\right)$; Curitiba $\left(\mathrm{C}_{3}\right)$, Fartura $\left(\mathrm{F}_{4}\right)$ e Guapiara (105).

As igualdades das direções médias verificadas entre as cinco áreas refletem, com $95 \%$ de probabilidade, contemporaneidade na colocação (ou resfriamento) dos diques e mostram quais áreas estiveram ativas, contemporaneamente,
Tabela 4 - Médias das direções de magnetização remanescente característica dos diques da região de Sapopema. Estas médias encontram-se representadas na Fig. 7B. Onde Médias indica a posição na rede, $N=$ total de sítios incluídos na média, os demais símbolos são os mesmos da Tabela 2 Table 4 - Mean characteristic remanent magnetization directions of the dikes from Sapopema region. These mean are represented in Fig.7B. Médias indicates the position on the stereonet, $\mathrm{N}=$ sites included in the mean, the other symbols are as in Table 2

\begin{tabular}{|c|c|c|c|c|c|c|c|}
\hline Médias & $\begin{array}{c}\text { Decl. } \\
\text { (\%) }\end{array}$ & $\begin{array}{c}\text { Incl. } \\
()^{\circ}\end{array}$ & $\begin{array}{l}695 \\
0\end{array}$ & $k$ & $\bar{R}$ & $\mathbf{N}$ & Sítios \\
\hline$s_{1}$ & 359,2 & $-31,2$ & 7.7 & 100,7 & 4,96027 & 5 & $\begin{array}{l}29,31,32, \\
33,34\end{array}$ \\
\hline$s_{2}$ & 349.4 & $-42,0$ & 6.2 & 79,4 & 7.91182 & 8 & $\begin{array}{l}24,25,27 . \\
28,30,35, \\
47,52\end{array}$ \\
\hline 46 & 176,4 & 58,7 & 6,0 & 126,5 & 5,960 & - & $\begin{array}{l}46 \text { - dados } \\
\text { da Tabela } 2\end{array}$ \\
\hline
\end{tabular}

durante os episódios intrusivos ocorridos no Arco de Ponta Grossa.

A direção de polaridade normal $\mathrm{F}_{2}$ de Fartura (Fig.7A) e reversa $\mathrm{C}_{4}$ de Curitiba (Fig.7D), não encontraram correspondentes nas outras áreas, isto sugere que quando o campo geomagnético apresentava estas direções somente Fartura e Curitiba estavam ativas.

Para uma melhor visualização dos eventos ou episódios intrusivos ocorridos no Arco de Ponta Grossa e, conse- 

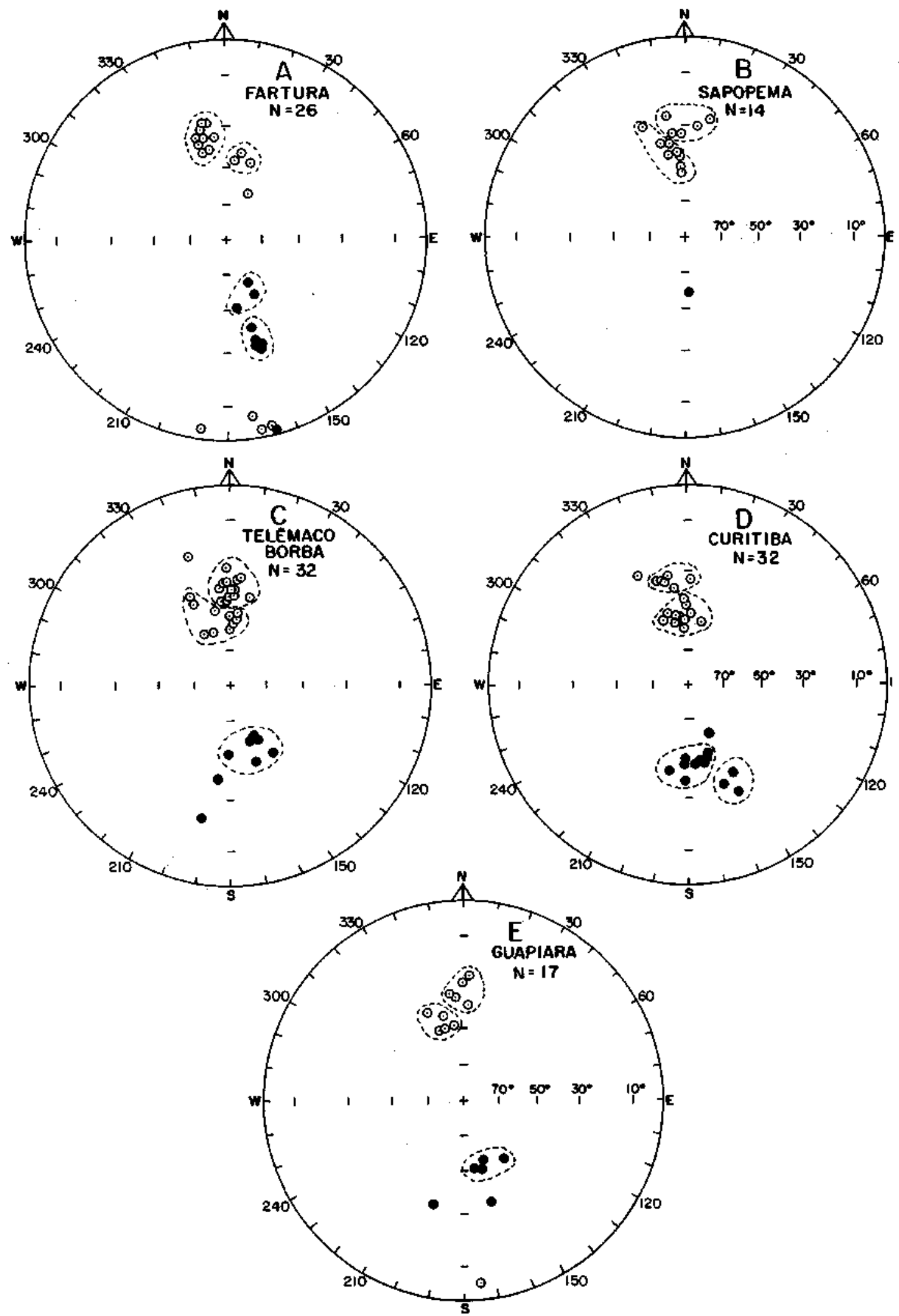

Figura 6 - Direções de magnetização dos diques das cinco áreas de maior concentração dos mesmos. Os símbolos vazios representam polaridade normal e os cheios polaridade reversa do campo geomagnético

Figure 6 - Magnetization directions of the dikes from the five areas where they are more concentrated. Open and solid symbols correspond to normal and reverse polarities of the geomagnetic field 
Tabela 5 - Médias das direções de magnetização remanescente característica dos diques da região de Telêmaco Borba. Estas médias encontram-se representadas na Fig. 7C. Onde Médias indica a posição na rede, $N=$ total de sítios incluídos na média, os demais símbolos são os mesmos da Tabela 2

Table 5 - Mean characteristic remanent magnetization directions of the dikes from Telêmaco Borba region. These mean are represented in Fig. $1 C$, Médias indicates the position on the stereonet, $\mathrm{N}=$ sites included in the mean, the other symbols are as in Table 2

\begin{tabular}{|c|c|c|c|c|c|c|c|}
\hline Médias & $\begin{array}{c}\text { Decl. } \\
(9)\end{array}$ & $\begin{array}{c}\text { Incl. } \\
(0)\end{array}$ & $\begin{array}{l}\alpha 95 \\
(?)\end{array}$ & $\mathbf{k}$ & $\mathrm{R}$ & $\mathbf{N}$ & Siltios \\
\hline $\mathbf{T}_{1}$ & 359.4 & $.37,7$ & 2,9 & 202,5 & 12,94075 & 13 & $\begin{array}{l}36,41,42,43, \\
50,51,53,60, \\
66,68,69,70 \\
71\end{array}$ \\
\hline$T_{2}$ & 349,3 & $-50,9$ & 6,6 & 54,5 & 9,83481 & 10 & $\begin{array}{l}38,40,54,55, \\
56,57,61, \\
63,64,67\end{array}$ \\
\hline$T_{3}$ & 160,3 & $-52,8$ & 7,4 & 83,0 & 5,93973 & 6 & $\begin{array}{l}37,39,45,49, \\
58,65\end{array}$ \\
\hline 44 & 341,8 & $-21,0$ & 3,1 & 246,0 & 9,963 & - & $\begin{array}{l}6 \text { dados da } \\
\text { Tabela } 2\end{array}$ \\
\hline 59 & 192,7 & 21,7 & 1.3 & 1460 & 8,995 & - & $\begin{array}{l}99 \text { dados da } \\
\text { Tabela } 2\end{array}$ \\
\hline 62 & 186,8 & 39,5 & 1.7 & 167,6 & 42,749 & - & $\begin{array}{l}62 \text { dados da } \\
\text { Tabela } 2\end{array}$ \\
\hline
\end{tabular}

Tabela 6 - Médias das direções de magnetização remanescente característica dos diques da região de Curitiba. Estas médias encontram-se representadas na Fig. $7 D$. Onde Médias indica a posição na rede, $N=$ total de sítios incluídos na média, os demais símbolos são os mesmos da Tabela 2 Table 6 - Mean characteristic remanent magnetization directions of the dikes from Curitiba region. These mean are represented in Fig.7D. Médias indicates the position on the stereonet, $\mathrm{N}=$ sites included in the mean, the other symbols are as in Table 2

\begin{tabular}{|c|c|c|c|c|c|c|c|}
\hline $\begin{array}{c}\text { Medias } \\
\left({ }^{\circ}\right)\end{array}$ & $\begin{array}{c}\text { Decl. } \\
\left({ }^{\circ}\right)\end{array}$ & $\begin{array}{l}\text { Inct. } \\
()^{\circ}\end{array}$ & $\alpha 95$ & $\mathbf{k}$ & $\mathbf{R}$ & $\mathbf{N}$ & Sítios \\
\hline $\mathrm{C}_{1}$ & 349,5 & $-34,4$ & 4,4 & 232,9 & 5,97853 & 6 & $\begin{array}{l}74,76.79,82 \\
93,99\end{array}$ \\
\hline $\mathrm{C}_{2}$ & 353,6 & $-51,8$ & 3,4 & 160,2 & 11.93350 & 12 & $\begin{array}{l}75,78,80,85, \\
96,97,100, \\
101,102,104, \\
122,123\end{array}$ \\
\hline$c_{3}$ & 156.7 & 33,2 & 8,8 & 196,6 & 2,98982 & 3 & $79,95,103$ \\
\hline $\mathrm{C}_{4}$ & 175,7 & 44,7 & 4,6 & 124,2 & 8,93556 & 9 & $\begin{array}{l}81,83,86,87, \\
90,91,92,94, \\
98\end{array}$ \\
\hline 72 & 335,8 & $-28,1$ & - & - & - & 1 & $\begin{array}{l}72 \text { dados da } \\
\text { Tabela } 2\end{array}$ \\
\hline 77 & 160,6 & 54,2 & - & - & - & 1 & $\begin{array}{l}77 \text { dados da } \\
\text { Tabela } 2\end{array}$ \\
\hline
\end{tabular}

quentemente, das áreas contemporaneamente ativas, efetuou-se uma média das direções médias de magnetização consideradas estatisticamente iguais entre as cinco áreas. Estas médias encontram-se na Tabela 8 e foram representadas com seus respectivos círculos de confiança na Fig. 9, onde representou-se também as direções médias $F_{2}$ de Fartura e $\mathrm{C}_{4}$ de Curitiba.

De modo geral, os dados da Fig. 9 indicam que, provavelmente, ocorreu um total de pelo menos nove fases ou episódios intrusivos distintos no Arco de Ponta Grossa como um todo, dois dos quais de caráter localizado, isto é, um deles
Tabela 7 - Médias das direções de magnetização remanescente característica dos diques da região de Guapiara. Estas médias encontram-se representadas na Fig. 7 E. Onde Médias indica a posição na rede, $N=$ total de sítios incluídos na média, os demais símbolos são os mesmos da Tabela 2 Table 7 - Mean characteristic remanent magnetization directions of the dikes from Guapiara region. These mean are represented in Fig.7E. Médias indicates the position on the stereonet, $\mathrm{N}=$ sites included in the mean, the other symbols are as in Table 2

\begin{tabular}{cccccccc}
\hline Médias & $\begin{array}{c}\text { Decl. } \\
\left({ }^{\circ}\right)\end{array}$ & $\begin{array}{c}\text { Incl. } \\
\left({ }^{\circ}\right)\end{array}$ & $\begin{array}{c}\alpha 95 \\
\left({ }^{\circ}\right)\end{array}$ & $k$ & $R$ & $N$ & Sítios \\
\hline$G_{1}$ & 357,7 & $-31,9$ & 6,1 & 155,7 & 4,97431 & 5 & $\begin{array}{l}108,109,110, \\
111,112\end{array}$ \\
$G 2$ & 343,7 & $-46,4$ & 5,9 & 167,9 & 4,97618 & 5 & $\begin{array}{l}106,107,117, \\
133,134\end{array}$ \\
$G_{3}$ & 161,3 & 53,2 & 8,4 & 121,4 & 3,97528 & 4 & $\begin{array}{l}113,131,132, \\
135\end{array}$ \\
105 & 165,8 & 34,8 & 1,8 & 564,5 & 11,981 & $-\begin{array}{l}105 \text { dados da } \\
\text { Tabela 2 }\end{array}$ \\
114 & 196,2 & 32,3 & 6,9 & 40,5 & 11,728 & $\begin{array}{l}- \\
114 \text { dados da } \\
\text { Tabela 2 }\end{array}$ \\
118 & 174,1 & $-4,1$ & 15,9 & 13,1 & 7,464 & $\begin{array}{l}118 \text { dados da } \\
\text { Tabela 2 }\end{array}$ \\
\hline
\end{tabular}

identificado apenas na área de Fartura (Média $\mathrm{V}$ ou $\mathrm{F}_{2}$ da Fig. 7A) e outro, apenas em Curitiba (Média VIII ou $\mathrm{C}_{4}$ da Fig. 7D). Um terceiro episódio foi registrado somente nas áreas de Fartura e Guapiara (direções intermediárias ou anômalas, Média IX). Os dados sugerem ainda, que somente durante uma fase intrusiva todas as áreas estiveram ativas (Média VI). Entretanto, essa fase foi menos expressiva nas áreas de Sapopema e Curitiba como é evidencidado pela ocorrência de somente um dique, em cada uma delas, com essa direção de magnetização (Tabela 8).

Desse modo, as áreas que estiveram mais vezes ativas foram Fartura (Figs. 7A e 9), Guapiara (Figs. 7E e 9) e Curitiba (Figs. 7D e 9).

As diferentes direções de magnetização encontradas para os diques do Arco de Ponta Grossa, provavelmente não estão associadas a diferenças significativas de idades radiométricas, mas devem estar refletindo mudanças na direção do campo geomagnético devido à variação secular e às inversões de polaridade. Considerando-se as escalas de tempo em que ocorrem esses fenômenos, da ordem de milhares de anos, os métodos radiométricos disponíveis, dificilmente poderiam detectar as diferenças temporais na atividade intrusiva do Arco.

DISCUSSÃO E CONCLUSÕES Os resultados paleomagnéticos apresentados neste trabalho permitem afirmar que o Arco de Ponta Grossa foi palco de uma atividade intrusiva que se processou em fases ou episódios distintos (Fig. 4), que devem ter ocorrido em um intervalo de tempo muito curto, mas suficiente para cobrir, pelo menos, um ciclo da variação secular.

A análise feita nas áreas de maior concentração dos diques, Fartura, Sapopema, Telêmaco Borba, Curitiba e Guapiara, indicou a ocorrência de mais de um episódio intrusivo dentro de cada área, dos quais pelo menos três puderam ser identificados (Figs. 7 e 9).

A comparação das direções médias de magnetização das cinco áreas permitiu verificar quais delas estavam ativas durante uma mesma fase intrusiva, além de indicar episódios localizados como aqueles ocorridos em Fartura, Curitiba e Fartura-Guapiara. Este último registrou uma direção típica de excursão ou inversão do campo geomagnético (Fig. 9). Somente na fase que gerou a direção Média VI da Fig. 9, é que todas as áreas estiveram contemporaneamente ativas. 


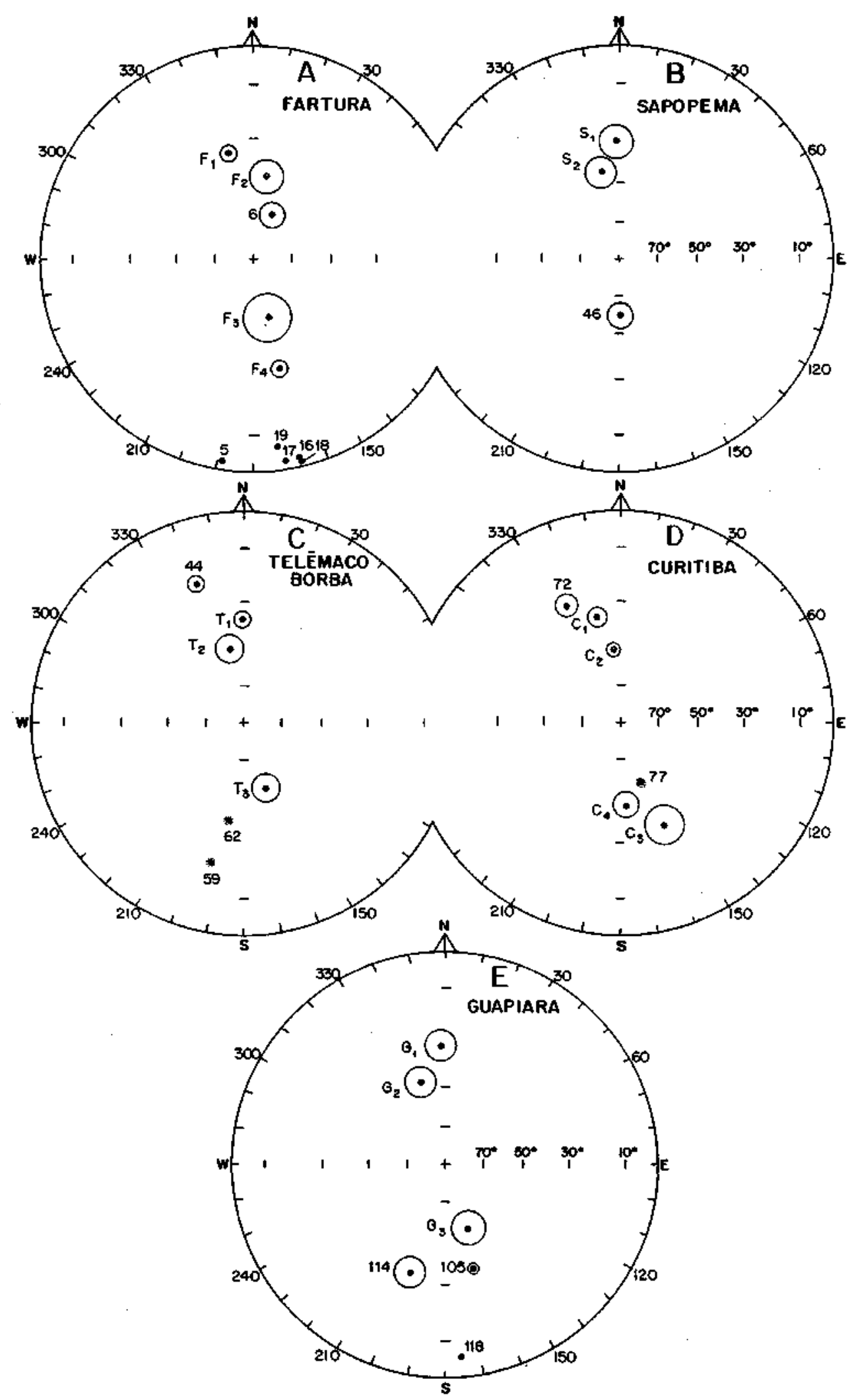

Figura 7 - Direções médias de magnetização para as cinco áreas, com seus respectivos círculos de $95 \%$ de confiança. Os dados encontram-se nas Tabelas 2 e 3 a 7. Os símbolos vazios representam polaridade normal e os cheios polaridade reversa do campo geomagnético

Figure 7 - Mean magnetization directions to the five areas with their respective 95\% confidence circles. Data are in Tables 2 and 3 to 7 . Open and solid symbols correspond to normal and reverse polarities of the geomagnetic field 


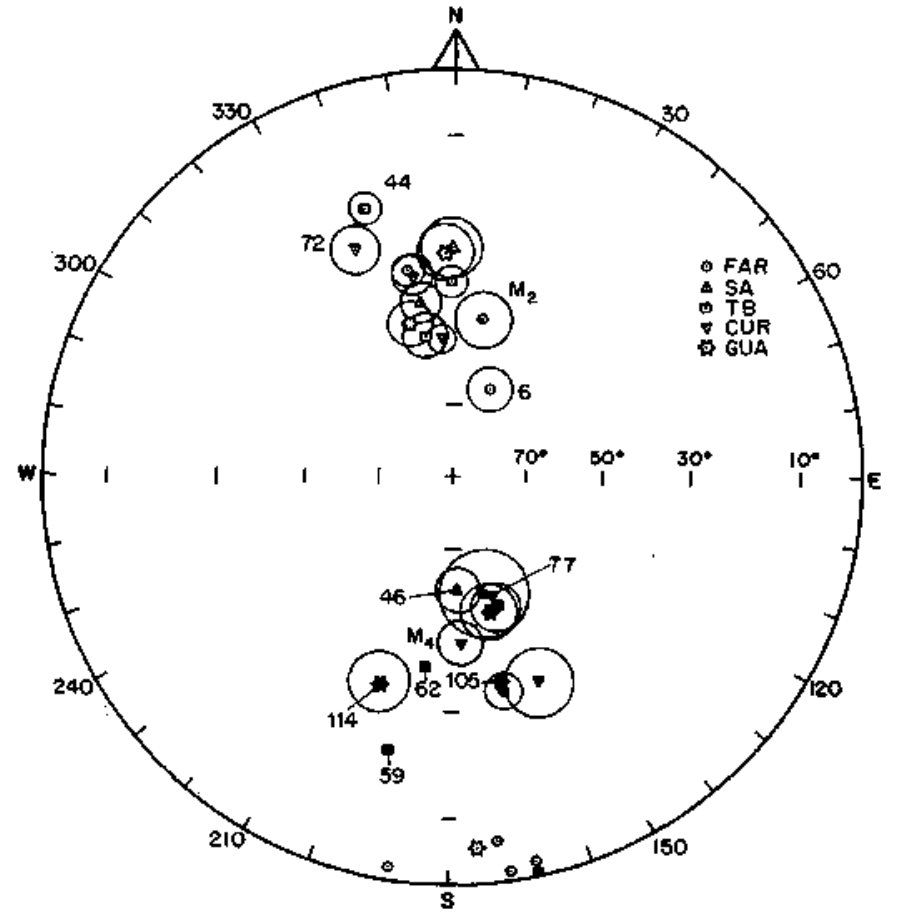

Figura 8 - Direções médias de magnetização dos diques de todas as áreas, juntamente com seus respectivos círculos de $95 \%$ de confiança. FAR=Fartura, SA=Sapopema, $T B=$ Telêmaco Borba, CUR=Curitiba e GUA=Guapiara. Os símbolos vazios representam polaridade normal e os cheios polaridade reversa do campo geomagnético Figure 8 - Mean magnetization directions of the dikes from all areas with their $95 \%$ confidence circles. FAR=Fartura, SA=Sapopema, TB=Telêmaco Borba, CUR=Curitiba and GUA=Guapiara. Open and solid symbols correspond to normal and reverse polarities of the geomagnetic field

Dessa forma os dados sugerem que o Arco de Ponta Grossa foi afetado por nove fases intrusivas principais.

Ferreira (1982) acredita que o material magmático que originou os diques surgiu através dos alinhamentos existentes no Arco de Ponta Grossa. Os dados aqui apresentados não descartam essa possibilidade, no entanto, os diques não foram condicionados exclusivamente por esses alinhamentos, uma vez que foi possível verificar a presença de diques com direções estruturais diferentes das direções apresenta-

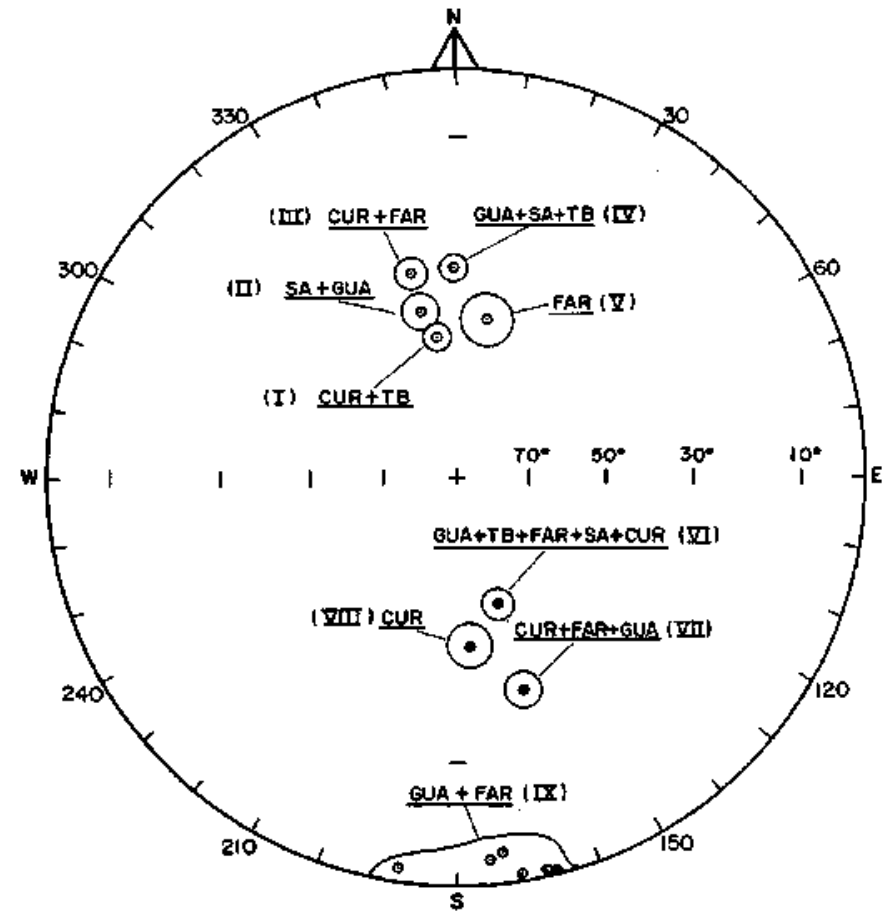

Figura 9 - Direções médias de magnetização dos diques, consideradas estatisticamente iguais, juntamente com seus respectivos círculos de $95 \%$ de confiança. Os números em romanos identificam as médias relacionadas na Tabela 8. Os símbolos vazios representam polaridade normal e os cheios polaridade reversa do campo geomagnético. $F A R=$ Fartura,$\quad S A=$ Sapopema,$\quad T B=$ Telêmaco Borba , $C U R=$ Curitiba e $G U A=$ Guapiara

Figure 9 - Mean magnetization directions of the dikes considerated statistically iqual with their respective $95 \%$ confidence circles. Roman numbers are related to the mean in Table 8. Open and solid symbols correspond to normal and reverse polarities of the geomagnetic field. $\mathrm{FAR}=$ Fartura, $\mathrm{SA}=$ Sapopema, $\mathrm{TB}=$ Telêmaco Borba, $\mathrm{CUR}=$ Curitiba e GUA $=$ Guapiara

das pelos alinhamentos (NW). Foi possível ainda verificar que não há uma relação temporal entre as diferentes direções estruturais observadas, isto é, não há uma relação entre as direções estruturais dos diques e as direções do campo geomagnético registradas (Fig.5). Isto significa que todos os

Tabela 8 - Médias das direções de magnetização remanescente característica dos diques das áreas consideradas estatisticamente iguais. Os números romanos indicam a posição na rede da Fig. 9, N=número total de sítios incluídos no cálculo da média. Os demais símbolos são os mesmos da Tabela 2. (*) a média não foi calculada por se tratar de uma direção que representa ou uma inversão de polaridade ou excurção do campo geomagnético

Table 8 - Mean characteristic remanent magnetization directions of the dikes from areas considerated statistically iquals. The roman numbers indicate the position on the stereonet of the Fig. 9, N=sites included in the mean, the other symbols are as in Table 2. $\left(^{*}\right)$ the mean was not calculated because this direction may be representing polarity inversion of the geomagnetic field

\begin{tabular}{|c|c|c|c|c|c|c|c|c|}
\hline Motias & $\begin{array}{c}\text { Decl. } \\
(9)\end{array}$ & $\begin{array}{c}\text { Incl. } \\
(9)\end{array}$ & $\begin{array}{c}\alpha 95 \\
(9)\end{array}$ & $\mathbf{k}$ & $\mathbf{R}$ & $\mathrm{N}$ & Pol & Areas consideradas estatisticamente iguais \\
\hline I & 352,2 & $-51,5$ & 3,4 & 85,5 & 20,76611 & 21 & $\mathbf{N}$ & Curitiba $\left(C_{2}\right)+$ Telêmaco Borba $\left(T_{\eta}\right)$ \\
\hline II & 347,3 & $.43,8$ & 4,3 & 92,3 & 12,87005 & 13 & $\mathbf{N}$ & Guapiara $\left(\mathrm{G}_{2}\right)+$ Sapopema $\left(S_{2}\right)$ \\
\hline III & 347,5 & $-35,7$ & 2,4 & 223,6 & 16,92843 & 17 & $\mathrm{~N}$ & Curitiba $\left(\mathrm{C}_{1}\right)+$ Fantura $\left(\mathrm{F}_{1}\right)$ \\
\hline $\mathbf{r V}$ & 359,0 & $-35,0$ & 2,6 & 138,9 & 22,84162 & 23 & $\mathbf{N}$ & Guapiara $\left(G_{1}\right)+$ Sapopema $\left(S_{1}\right)+$ Tel. Borba $\left(T_{1}\right)$ \\
\hline $\mathrm{v}$ & 9,8 & $-45,7$ & 6,7 & 338,9 & 2,99410 & 3 & $\mathbf{N}$ & Fanura $\left(F_{2}\right)$ \\
\hline VT & 162,4 & 54,4 & 3,6 & 111,3 & 14,87421 & 15 & $\mathbf{R}$ & $\begin{array}{l}\text { Tel. Borba }\left(T_{1}\right)+\text { Sapop. }(46)+\text { Far }\left(F_{3}\right)+\operatorname{Cur}(77)+ \\
\text { Gua }\left(G_{3}\right)\end{array}$ \\
\hline VII & 162,8 & 33,4 & 3,5 & 210,5 & 8,96200 & 9 & $\mathbf{R}$ & Curitiba $\left(C_{3}\right)+$ Fartura $\left(F_{4}\right)+$ Guapiara $(105)$ \\
\hline VIII & 175,7 & 44,7 & 4,6 & 124,2 & 8,93556 & 9 & $\ddot{R}$ & Curitiba (C.) \\
\hline $\mathbf{L} *$ & - & - & -_ & - & - & 6 & 1 & Fartura + Guspiara, direçāo intermediária \\
\hline
\end{tabular}


sistemas de fraturas puderam ser preenchidos concomitatttemente.

Os dados gjeoquímicos dos diques, obtidos nas mesmas amostras estudadas paleomagneticamente (Benini, 1992) mostraram que há diferenças significativas entre os diques aflorantes nas áreas de maior concentração dos mesmos. As áreas de Fartura e Guapiara são geoquimicamente semelhantes e, sob esse aspecto, mais evoluídas, enquanto a área de Curitiba é a mais primitiva. As áreas de Sapopema e Telêmaco Borba são semelhantes entre si, mas ocupam uma posição distinta entre Fartura-Guapiara e Curitiba.

Os dados geoquímicos associados aos dados paleomagnéticos mostraram que, uma mesma fonte pôde estar ativa em tempos diferentes, tendo em vista que nas diversas áreas ocorreram fases intrusivas com polaridades normal e reversa do campo geomagnético (Figs. 6 e 7), sem entretanto implicar em mudanças significativas na composição química dos diques. Por outro lado, fontes distintas puderam estar contemporaneamente ativas como é o caso, por exemplo, (Fig. 9, Média III) das áreas de Fartura (mais evoluída) e Curitiba (mais primitiva).

Agradecimentos A autora gostaria de agradecer à Profa. Dra. Mareia Ernesto pela orientação prestada durante a realização deste trabalho, a FAPESP e ao CNPq pelo apoio financeiro prestado, sem o qual este trabalho não se realizaria.

\section{REFERÊNCIAS BIBLIOGRÁFICAS}

ALGARTE, J.P. 1972. Influência dos arqueamentos cratônicos no conhecimento das alcalinas nos Estados de São Paulo e Paraná. In: CONGR. BRÁS GEOL 26. Belém, 1912 Anais Belém, SBG. v. 1, p. 65-89.

ALMEIDA, F.F.M. 1967. Origem e evolução da plataforma brasileira. Boi. Div. Geol. Min., Rio de Janeiro, 241:36.

ALMEIDA, F.F.M. 1983. Relações tectônicas das rochas alcalinas Mesozóicas da região meridional da plataforma Sul-Americana. Rev. Bras. Geoc., 13(3):139-158.

ALMEIDA, F.F.M. 1986. Distribuição regional e relações tectônicas do magmatimo pós-Paleozóico no Brasil. Rev. Bras. Geoc. 16(4):325-349

ASMUS, H.E. \& PORTO, R. 198.0. Diferenças nos estágios iniciais da evolução da margem continental brasileira: possíveis causas e implicações. In: CONGR. BRÁS. GEOL., 31. Camboriú, 1980. Anais... Camboriú, SBG. v. 1, p. 225-239.

ASMUS, H.E. 1981. Relacionamento genético de feições geológicas da margem continental sudeste brasileira e da área continental adjacente. In: SIMP. GEOL. SUL, 3. Curitiba 1981. Ami... Curitiba, SBG, v. 1, p. $262-270$.

BELLIENI. G.; COMIN-CHIARAMONTI, P.; MARQUES, L.S.; MELFI, A.J.; NARDY, A.J.R.; PICCIRILLO, E.M. \& ROISENBERG, A. 1984. High and $\mathrm{Low}_{-} \mathrm{TiO}_{2}$ flood basalts from the Paraná plateau (Brazil): petrology and geochemical aspects bearing on their mantle origin. Neus. Jarh. Miner. Abh., 150:273-306.

BENINI, S. 1992. Sciami di dicchi nel S-E Brasile: petrologia, geochimica isotopica e implicazioni geodinamiche. Trieste. 123 p. (Tese de Doutorado, Intitulo de Mineralogia e Petrografia da Universidade deTrieste, Itália).

BUDDINGTON, A.F. \& LINDSLEY, D.H. 1964. Iron-titanium oxides minerals and synthetic equivalents. J. Petrol., 5:310

ERNESTO, M.; PACCA, I.G.; HIODO, F.Y. \& NARDY, A.J.R 1990 Palaeomagnetism of the Mesozoic Serra Geral Formation, southern Brazil. Phys. Earth Planet. Inter., 64:153-175.

FERREIRA, F.J.F. 1982. Integração de dados aeromagnéticos e geológicos: configuração e evolução tectônica do Arco de Ponta Grossa. São Paulo. 169 p. (Dissertação de Mestrado, Instituto de Geociências da USP).

FERREIRA, F. J.F.; MORAES, R.A.V.; FERRARI, M.P. \& VIANNA, R.B. 1981. Contribuição ao estudo do alinhamento estrutural de Guapiara. In: SIMP. GEOL. SUL, 3. Curitiba 1981. Atas... Curitiba, SBG, v. 1, p. $226-240$.

FISHER, R.A.. 1953. Dispersion on a sphere. Proc. R. Soe. London, 217:291-305

FÚlFARO, V.J. \& SUGUIO, K. 1967. Campos de diques de diabásio da da Bacia do Paraná. Boi. Soe. Brás. Geol, 16(2):23-37.

FÚlFARO, V.J. \& Suguio, K. 1974. Geologia da região de Fartura. In: CONGR. BRÁS. GEOL., 26. Porto Alegre, 1974. Anais... Porto Alegre, SBG. v. 4, p. 173-180.

HAGGERTY, S.E. 1981. Oxidation of opaque mineral oxides in basalts. In: Rumble, D. ed. Oxide Minerals; Reviews in Mineralogy, Vol 3, Chapter 4, (Mineral. Soc. of Am., Washington, D.C.)

IPT. 1981. Mapa geológico do Estado de São Paulo, escala 1: 500.000. Intitulo de Pesquisa Tecnológica- Governo do Estado de São Paulo

MARINI. O.J.; FUCK, R.A. \& TREIN, E. 1967. Inirusivas básicas Jurássico-Creláceas do Primeiro Planallo do Paraná. Boi. Paranaense de Geoc. Curiliba, 23-25:307-324

MCFADDEN, P.L. \& LOWES, F.J. 1981. The discriminalion of mean direclions drawn from Fisher distributions. Geophys. J. R. Astr. Soc., 67:19-33.

MINEROPAR. 1989. Mapa geológico do Estado do Paraná, escala $1: 650.000$. Minerais do Paraná S.A., Governo do Estado do Paraná.

OLIVEIRA, E.P. \& MONTES, M.L. 1984. Os enxames de diques máficos do Brasil. In: CONGR. BRÁS. GEOL., 33. Rio de Janeiro, 1984 Anais... Rio de Janeiro, SBG. v.1, p. 4137-41155.

PICCIRILLO, EM; MELFI, A.J.; COMIN-CHIARAMONTI, P.; BELLIENI, G.; ERNESTO, M.; MARQUES.L.S.; NARDY, A.J.R.;
PACCA, I.G., ROISEMBERG, A. \& STOLFA, D. 1988. Continental flood volcanism from the Paraná Basin (Brazil). In: MacDougal, J.D. ed. Continenial Flood Basalls, Kluwer Acad. Publ. 195-238.

PICCIRILLO, EM; COMIN-CHIARAMONTI, P.; MELFI, A.J.; STOLFA, D.; BELLIENI, G.; MARQUES.L.S.; NARDY, A.J.R.; PINESE, J.P.P.; RAPOSO, M.I.B. \& ROISEMBERG, A. 1989. Pelrochemical of conlinenlal flood basalt-rhyolite suites and related intrusives from lhe Paraná Basin (Brazil). In: Piccirillo, E.M.; Melfl, A.J. eds. The Mesozoic Flood Volcanism of lhe Paraná Basin: Pelrogenelic and Geophysical Aspecls. 1AG/Universidade de São Paulo, Brasil. 107-156.

PICCIRILLO, E.M.; BELLIENI, G.; CAVAZZINI, G.; COMIN-CHIARAMONTI, P.; PETRINI.R.; MELFI, A.J.; PINESE, J.P.P.; ZANTADESCHI, P. \& DE MIN, A. 1990. Lower Creiaceous tholeiitic dyke swarm from the Ponta Grossa Arch (Southeasl Brazil): Petrology, $\mathrm{Sr}-\mathrm{Nd}$ isotopes and genetic relationships with the Paraná flood volcanics. Chem. Geol., 89:19-48.

PINESE, J.P.P. 1989. Caracierização pelrológica e geoquímica dos diques do Arco de Ponla Grossa. São Paulo. 196 p. (Dissertação de Mestrado. Instituto Astronômico e Geofísico da USP).

RAPOSO, M.I.B. \& ERNESTO, M. 1989. Rochas intrusivas básicas do Arco de Ponta Grossa: resultados paleomagnéticos preliminares. Rev. Bras. Geoc., 19:393-400.

RAPOSO, M.I.B. \& ERNESTO, M. 1991. Direções estruturais dos diques máficos do Arco de Ponta Grossa determinadas através da anisotropia de suscetibilidade magnética. In: SIMP. NACIONAL ESTUDOS TECTÔNICOS, 3. Rio Claro SP. (Boletim de Resumos).

RAPOSO, M.I.B. 1992. Paleomagnetismo do enxame de diques do Arco de Ponta Grossa, São Paulo 104 p. (Tese de Doutoramento Instituto Astronômico e Geofísico da USP).

RENNE, P.R. \& ERNESTO. M.; PACCA. I.G.; COE. R. \& GLEN, J. 1992 The age of Paraná flood, volcanics rifiting of Gondwanaland and Jurassic-Cretaceous boundary. Science, 258:975-979.

ROCHA-CAMPOS, A.C.;CORDANI, U.G.; KAWASHITA, K.; SONOKI, H.M. \& SONOKI, I.K. 1988. Age of the Paraná flood volcanism. In: Piccirillo, E.M.; Melfl, A.J. eds. The Mesozoic Flood Volcanism of lhe Paraná Basin: Pelrogenelic and Geophysical Aspects. IAG/Universidade de São Paulo, Brasil. 25-46.

SIAL, A.N.; OLIVEIRA, E.P. \& CHODHURI, A. 1987. Mafic dyke swarms of Brazil. In: Halls, H.C.; Fahrig, W.F. eds. Mafic Dyke Swarms. Geological Association of Canada, Special paper 34:467-481.

SOARES, P.C.; BARCELLOS, P.E.; CSORDAS, S.M.; MATOS, J.T.; BALLIEIRO, M.G. \& MENESES, P.R. 1982. Lineamentos em imagens de Landsat e Radar e suas aplicações no conhecimenio leciônico da Bacia do Paraná. In: SIMP. BRAS. SENSORIAMENTO REMOTO, Brasília, 2:143-156.

USSAMI, N.; KOLISNYK, A.; RAPOSO, M.I.B.; FERREIRA, F.J.F.; MOLINA, E.C. \& ERNESTO, M. 1991. Deieclabilidade de diques do Arco de Ponla Grossa: um estudo integrado de magnetometria terrestre/aérea e magnelismo de rocha. Rev. Bras. Geoc., 21(4):317-327.

VIEIRA, A.J. 1973. Geologia do ceniro e nordesie do Paraná e centro-sul de São Paulo. In: CONGR. BRÁS. GEOL. 26. Aracaju, 1973.A«a/s... Ararcajú, SBG. v. 3, p. 259-277.

ZALÁN, P.V.; WOLFF, S.; CONCEIĈ̃O, J.C.J.; ASTOLFI, M.A.M.; VIEIRA, I.S.; APPI, V.T.; ZANOTTO, O.A. \& MARQUES, A. 1988. Tectonics and sedimentation of the Paraná Basin. In: INTERNATIONAL GONDWANA SYMPOSIUM, 7. São Paulo, 1988. Proceedings... São Paulo, p. 83-117.

ZIJDERVELD, J.D.A. 1967. A.C demagnetization of rocks: analysis of results. In: Collinson, D.W.; Creer, K.M.; Runcorn, S.K. eds. Methods in Paleomagnetism. Elsevier Sci Pub. Co., Amsterdam, p. 254-286.

MANUSCRITO A826 Recebido em 6 de fevereiro de 1995 ã̃o do autor em 20 de marco de 1996 Revisão aceita em I de abril de 1996 